\title{
Mapping the Ethicality of Algorithmic Pricing: A Review of Dynamic and Personalized Pricing
}

\author{
Peter Seele ${ }^{1}(1) \cdot$ Claus Dierksmeier $^{2} \cdot$ Reto Hofstetter $^{3} \cdot$ Mario D. Schultz $^{4}$
}

Received: 13 July 2018 / Accepted: 25 November 2019 / Published online: 10 December 2019

(c) The Author(s) 2019

\begin{abstract}
Firms increasingly deploy algorithmic pricing approaches to determine what to charge for their goods and services. Algorithmic pricing can discriminate prices both dynamically over time and personally depending on individual consumer information. Although legal, the ethicality of such approaches needs to be examined as often they trigger moral concerns and sometimes outrage. In this research paper, we provide an overview and discussion of the ethical challenges germane to algorithmic pricing. As a basis for our discussion, we perform a systematic interpretative review of 315 related articles on dynamic and personalized pricing as well as pricing algorithms in general. We then use this review to define the term algorithmic pricing and map its key elements at the micro-, meso-, and macro levels from a business and marketing ethics perspective. Thus, we can identify morally ambivalent topics that call for deeper exploration by future research.
\end{abstract}

Keywords Ethical pricing $\cdot$ Algorithmic pricing $\cdot$ Dynamic pricing $\cdot$ Personalized pricing $\cdot$ Discrimination

\section{Introduction}

Would you pay more for a Coke on a hot day? As early as 1999, Douglas Ivester the CEO of Coca-Cola discussed the potential introduction of temperature-sensitive vending machines that adjusts the price according to the outside temperature (Phillips 2005). For him, the answer was clear: "Coca-Cola is a product whose utility varies from moment to moment. In a final summer championship, when people meet in a stadium to enjoy themselves, the utility of a chilled Coca-Cola is very high. So it is fair it should be more expensive. The machine will simply make this process automatic." (Phillips 2005, p. 302).

In the public outcry that followed Ivester's remarks, Coca-Cola faced accusations of gouging and consumer exploitation, as people firmly rejected the idea of such a machine (Leonhardt 2005). 20 years after, the temperaturesensitive vending machine remains a rumor. However, where until recently, fixed and uniform prices seemed to be the pillar on which the capitalist edifice rested, algorithms are now in charge to observe customers and set prices dynamically and even personalized according to identified customer features (Chen and Gallego 2019; Chen et al. 2016b; Koh et al. 2017). Today's algorithms are far more advanced than any beverage vending machine one could think of decades ago. The capacities of this new generation of algorithms, we hold, 
are not mere technicalities to be silently passed over. Rather, they constitute potentially a thoroughgoing revolution in how humans and algorithms interact commercially, online as well as offline. Although research on algorithmic pricing has substantially increased in the last decade (Ajorlou et al. 2018; Chen et al. 2016b; Peura and Bunn 2015; Spann et al. 2015), a comprehensive ethical understanding of the expanding subject is still lacking (Buhmann et al. 2019; Calvano et al. 2019; Elegido 2011, 2015; Martin 2018, 2019a; Mercier-Roy and Mailhot 2019). Our article wants to make a first step in the direction of closing this lacuna.

By a systematic review of the literature from a business and marketing ethics perspective, we offer a first chart of the topical territory, clarifying the underlying concepts and structures of algorithmic pricing and showing where major ethical problems arise. In what follows, we examine research literature on pricing algorithms in general, ethical and legal issues, pricing policies, personalization models, inventory management, and electronic retail. By mapping the micro, meso, and macro levels of algorithmic pricing, we discuss how ethical aspects of algorithmic pricing relate to individual and aggregate agency within society. Adducing arguments from deontology, teleological, consequentialist ethics, social contract theory, and utilitarianism, we conclude with suggestions of how these major schools of ethical thought would characterize the morally relevant aspects of algorithmic pricing. While by no means exhaustive, this list of schools is to serve as a first approximation to the subject. Future research would, of course, have to amend our endeavor both by delving deeper into each of the surveyed schools and by augmenting the list with further ethical theories (such as for instance, care ethics $^{1}$ ).

Overall, we contribute to the literature by making accessible to researchers and practitioners the current state of relevant marketing, law, economic, management, and computer science literature about algorithmic pricing. By delimiting such aspects that can without controversy be deemed morally good or bad from concerns still requiring deeper exploration, we show where research gaps exist and opportunities for future research lie. One core contribution of the review is a refined and ethically informed definition of algorithmic pricing (for details on a comparison with alternative definitions see chapter "Concepts and Definitions" below): Algorithmic pricing is a pricing mechanism, based on data analytics,

\footnotetext{
1 "For a definition of care ethics, see https://www.iep.utm.edu/careeth/" and additionally Gössling and van Liedekerke (2014); in recent years, care ethics has developed beyond its context of origin in feminist ethics so as to encompass the specificities brought on by starkly asymmetrical situations (helping/helpless person; adult/child; healthy/ incapacitated subject, etc.); a good intro into and survey of the field is given by: Held, Virginia. The Ethics of Care. New York, NY: Oxford University Press, 2006."
}

which allows firms to automatically generate dynamic and customer-specific prices in real-time. Algorithmic pricing can go along with different forms of price discrimination (in both a technical and moral sense) between individuals and/or groups. As such, it may be perceived as unethical by consumers and the public, which in turn can adversely affect the firm.

Further, we strive to connect to ethical debates on algorithmic accountability and algorithmic governance so as to highlight practical implications and the use of algorithmic pricing mechanisms.

\section{Literature Review}

\section{Research Method}

Since a host of differing methods are available to review and synthesize academic literature, a few words are in order concerning our proceedings. In this study, we follow an interpretive review approach (Suddaby et al. 2017). Interpretative reviews build on a thematic or inductive method to make sense of a literature body that is generally diverse in nature, consisting of qualitative, quantitative, and conceptual studies (Suddaby et al. 2017). In contrast to integrative reviews which are generally used to summarize and analyze quantitative literature with data similarity and well-specified constructs (e.g., via a meta-analysis, Schmidt and Hunter 2014), interpretative reviews are particularly valuable when there is less cohesion between the reviewed studies and thus, less construct, variable, and term clarity (Suddaby et al. 2017). Consequently, as the dynamic and personalized pricing literature is highly heterogeneous (i.e., qualitative, quantitative, and conceptual) with low construct clarity, stretching along multiple research fields, we adopt an interpretive approach (details below) to review the most relevant publications concerning Business and Marketing Ethics.

\section{Scope and Limitations}

Algorithmic pricing is based on different forms of computerassisted real-time pricing mechanisms (Angel and McCabe 2018; Calvano et al. 2019; Chen et al. 2016b; Faruqui and Sergici 2013). In this study, we focus on the two major types of algorithmic pricing, that is, dynamic and personalized pricing. The two pricing types are characterized and interpreted differently within scientific communities, as they stand at the frontier of and overlap with several research fields, predominantly Marketing, Operations Research/Management Science, Economics, Law and Computer science and not least Business and Marketing Ethics (Angel and McCabe 2018; Bar-Gill 2019; Cosguner et al. 2018; den Boer 2015; Elmaghraby and Keskinocak 2003; Gal 2019; 
Fig. 1 Research design

\begin{tabular}{|c|c|c|c|c|}
\hline \multicolumn{5}{|c|}{ Algorithmic Pricing } \\
\hline \multicolumn{5}{|c|}{ The Rise of Algorithmic Pricing: Concepts and Definitions } \\
\hline Ethical Issues & Legal Issues & $\begin{array}{l}\text { Pricing Algo- } \\
\text { rithms (51 arti- } \\
\text { cles) }\end{array}$ & $\begin{array}{l}\text { Pricing Policies } \\
\text { and Personaliza- } \\
\text { tion Models }\end{array}$ & $\begin{array}{l}\text { Inventory Man- } \\
\text { agement and } \\
\text { Electronic Retail }\end{array}$ \\
\hline \multicolumn{5}{|c|}{ Mapping the Ethicality } \\
\hline \multicolumn{2}{|c|}{ “Good” } & "Bad" & \multicolumn{2}{|c|}{ "Ambivalent" } \\
\hline \multicolumn{5}{|c|}{ Micro Level (individual) } \\
\hline \multicolumn{5}{|c|}{ Meso Level (intermediary trajectory) } \\
\hline \multicolumn{5}{|c|}{ Macro Level (aggregated population) } \\
\hline
\end{tabular}

Kummer and Schulte 2019; Mercier-Roy and Mailhot 2019; Obermiller et al. 2012). Dynamic pricing (sometimes also known as surge, yield or real-time pricing) generally refers to the practice of dynamically adjusting prices in order to achieve revenue gains, while responding to a given market situation with uncertain demand (Aviv and Vulcano 2012; Chen and Gallego 2019; Chen et al. 2016b). Personalized pricing is referred to as first-degree price discrimination, customized, or targeted pricing, and represents a pricing strategy "whereby firms charge different prices to different consumers based on their willingness to pay" (Choudhary et al. 2005, p. 1120). Although the two types substantially overlap and often apply in combination, we conducted two separate literature reviews on either type of algorithmic pricing. This is for genealogical reasons, as, from a technological point of view, dynamic pricing appeared considerably earlier than personalized pricing. Second, the two types vary in the degree of price discrimination, which, from a business and marketing ethics perspective, warrants two separate literature assessments. Lastly, the generic title algorithmic pricing, summarizing different forms of big data and computerized pricing mechanisms, only emerged recently with the rise of algorithms as a key component of digitalization (Bar-Gill 2019; Calvano et al. 2019; Chen et al. 2016a; Ettl et al. 2019; UK Competition and Markets Authority 2018). To account for technicalities of pricing algorithms in general, an additional targeted review was conducted, as algorithms represent the core of this pricing mechanism. Eventually, we synthesized the separate reviews to give a survey on the ethicality of the technology and its use. Figure 1 outlines the research design of this study.

\section{Data Collection and Selection Criteria}

We searched for relevant literature in four major electronic databases [Business Source Premier, Communication and Mass Media Complete (CMMC), Social Science Research Network (SSRN), Clarivate Analytics Web of Science]. Given the novelty and interdisciplinary nature of the topic of algorithmic pricing, we decided for openness of the sample and against formal sample inclusion criteria like top-tierjournals of a specific field. Also, many articles from informatics on pricing algorithms were published in informatics conference proceedings that we would have missed otherwise. The search for relevant articles included the following terms "dynamic pricing", "personalized pricing”, "personalised pricing", "customized pricing", and "customised pricing" "algorithmic pricing"; "pricing algorithm" appearing in the title, abstract, subject terms, or keywords. The search 
Table 1 Data collection and selection criteria

\begin{tabular}{|c|c|}
\hline Search terms & $\begin{array}{l}\text { "dynamic pricing"; "personalized pricing"; "personalised pricing"; "customized pricing"; "customised pricing"; "algorithmic } \\
\text { pricing"; "pricing algorithm" }\end{array}$ \\
\hline Language & English \\
\hline Time frame & No limitations \\
\hline Databases & $\begin{array}{l}\text { Business Source Premier, Communication and Mass Media Complete (CMMC), Clarivate Analytics Web of Science, Social Sci- } \\
\text { ence Research Network (SSRN) }\end{array}$ \\
\hline Inclusion & From journal or database, primarily related to dynamic/personalized pricing, accessible in full text \\
\hline Exclusion & $\begin{array}{l}\text { Letters to the editor, commentaries, tutorials, conference abstracts, opinions, viewpoints, as well as studies without direct relation } \\
\text { to dynamic/personalized pricing were excluded }\end{array}$ \\
\hline
\end{tabular}

timespan was not restricted, and the focus was set to articles published in English language. Table 1 provides an overview of the data collection and selection criteria.

The final dataset consisted of 315 articles $^{2}$ from over 80 different journals spanning a time period from 1980 to 2019 (184 articles about dynamic pricing and 80 about personalized pricing, 51 about pricing algorithms in general). The articles on dynamic and personalized pricing were reviewed and coded separately along emergent, and relatively salient clusters (Tables 2 and 3 ). In several consensus sessions, these clusters were discussed to refine and derive the ultimate themes that structure the following paragraphs. As the clusters of the individual reviews are largely identical, we combined the resulting themes of the dynamic and personalized pricing literature. Thus, the current state of discussion in the academic literature is provided along the four major themes of: (2) Ethical Issues: Consumer Behavior and Marketing Ethics, (3) Legal Issues, (4) Pricing Policies and Personalization Models, (5) Inventory Management. In addition, the first theme, informed by a targeted review of pricing algorithms, provides a general introduction to pricing algorithms that are used for both, dynamic and personalized pricing: (1) Pricing Algorithms in general.

\section{The Rise of Algorithmic Pricing}

The practice of algorithmic pricing emerged out of the concept of dynamic pricing, which became mainstream in the 1980s, after its successful use by American Airlines. Although the underlying mathematical concepts and models of dynamic pricing date back to the mid-twentieth century (see, e.g., Kincaid and Darling 1963), the more recent scientific and practitioner interest was triggered by seminal articles in the late 1980s and early 1990s (Belobaba 1987a, b, 1989; Gallego and van Ryzin 1994). Given that pricing

\footnotetext{
2 The full list of articles is provided as Supplementary File (see Online Appendix). The list was updated in September 2019 to account for the latest discussion on algorithmic pricing including the article DOIs for immediate access.
}

algorithms haven been around for quite some time, growing academic literature is not the only reason for their diffusion (Ajorlou et al. 2018; Chen et al. 2016a; Peura and Bunn 2015; Spann et al. 2015). Algorithms depend on data and their effectiveness grows in tandem with an increase in data input (Fisher et al. 2018; Miklós-Thal and Tucker 2019).

Algorithmic pricing therefore benefits substantially from the development of a whole new ecosystem, entailing rapidly advancing information and communication technologies and e-commerce systems (Cohen 2018). The shift to online retailing provides customers with easy access to their preferred goods and services out of their living room; having a global market at the fingertips with the possibility to compare prices and offers at any time of the day. Yet, the online environment also empowers companies to follow-up on the digital traces left behind so as to collect fine-grained consumer information. Enabled by continuous advancements in computing power and algorithmic complexity, this digital ecosystem is itself exemplary of a new type of data capitalism (Xia et al. 2019; Zuboff 2019). In this environment driven by 'big data,' companies have to act and respond quickly to constantly changing market conditions, adjusting their strategies based on available information and with the help of automated algorithms (Cohen 2018). One of the most crucial and effective variables that companies can manipulate to adjust to the market is the price, which can be technically altered in an online environment at close to zero cost $^{3}$ (Bitran and Caldentey 2003).

Algorithmic pricing has spread into multiple industries and is now considered a highly advanced business approach and key driver of business success in terms of increased profits (Cosguner et al. 2018; Fisher et al. 2018; Spann et al. 2015). Electricity and gasoline markets (Balmaceda and Soruco 2008; Faruqui and Sergici 2010), online retailing (Fisher et al. 2018), and even the sports and entertainment

\footnotetext{
${ }^{3}$ It is important to note that indirect, not monetary costs to changing prices may occur, such as increased attrition, or opportunity costs. Further, switching from one overall pricing modality to another can also lead substantial monetary costs for a firm (Adida and Özer 2019; Ellickson et al. 2012).
} 
Table 2 Dynamic pricing: themes with key publications

\begin{tabular}{|c|c|c|c|c|}
\hline Theme/cluster & Journal & Author (year) & Title & $\begin{array}{l}\text { Type of } \\
\text { algorithmic } \\
\text { pricing }\end{array}$ \\
\hline \multirow[t]{4}{*}{ Ethical issues } & Journal of Marketing Research & Bolton et al. (2010) & $\begin{array}{l}\text { How do price fairness percep- } \\
\text { tions differ across culture? }\end{array}$ & Dynamic \\
\hline & MIS Quarterly & Hinz et al. (2011) & $\begin{array}{l}\text { Price discrimination in e-com- } \\
\text { merce? An examination of } \\
\text { dynamic pricing in name-your- } \\
\text { own price markets }\end{array}$ & Dynamic \\
\hline & Journal of Consumer Research & Haws and Bearden (2006) & $\begin{array}{l}\text { Dynamic pricing and consumer } \\
\text { fairness perceptions }\end{array}$ & Dynamic \\
\hline & $\begin{array}{l}\text { Journal of the Academy of Mar- } \\
\text { keting Science }\end{array}$ & Weisstein et al. (2013) & $\begin{array}{l}\text { Effects of price framing on con- } \\
\text { sumers' perceptions of online } \\
\text { dynamic pricing practices }\end{array}$ & Dynamic \\
\hline \multirow[t]{4}{*}{ Legal issues } & Communications of the ACM & Gal (2019) & Illegal pricing algorithms & Dynamic \\
\hline & $\begin{array}{l}\text { Journal of Competition Law \& } \\
\text { Economics }\end{array}$ & Schwalbe (2018) & $\begin{array}{l}\text { Algorithms, machine learning, } \\
\text { and collusion }\end{array}$ & Dynamic \\
\hline & Harvard Business Review & Stucke and Ezrachi (2016) & $\begin{array}{l}\text { How pricing bots could form } \\
\text { cartels and make things more } \\
\text { expensive }\end{array}$ & Dynamic \\
\hline & Minnesota Law Review & Mehra (2016) & $\begin{array}{l}\text { Antitrust and the robo-seller: } \\
\text { competition in the time of } \\
\text { algorithms }\end{array}$ & Dynamic \\
\hline \multirow[t]{4}{*}{ Pricing policies } & $\begin{array}{l}\text { Manufacturing \& Service Opera- } \\
\text { tions Management }\end{array}$ & Maglaras and Meissner (2006) & $\begin{array}{l}\text { Dynamic pricing strategies for } \\
\text { multiproduct revenue manage- } \\
\text { ment problems }\end{array}$ & Dynamic \\
\hline & Marketing Science & Kopalle et al. (1996) & $\begin{array}{l}\text { Asymmetric reference price } \\
\text { effects and dynamic pricing } \\
\text { policies }\end{array}$ & Dynamic \\
\hline & Operations Research & Araman and Caldentey (2009) & $\begin{array}{l}\text { Dynamic pricing for non-per- } \\
\text { ishable products with demand } \\
\text { learning }\end{array}$ & Dynamic \\
\hline & Journal of Political Economy & Bergemann and Välimäki (2006) & $\begin{array}{l}\text { Dynamic pricing of new experi- } \\
\text { ence goods }\end{array}$ & Dynamic \\
\hline \multirow[t]{4}{*}{ Inventory management } & Operations Research & Besbes and Zeevi (2009) & $\begin{array}{l}\text { Dynamic pricing without know- } \\
\text { ing the demand function: } \\
\text { risk bound and near-optimal } \\
\text { algorithms }\end{array}$ & Dynamic \\
\hline & Management Science & $\begin{array}{l}\text { Elmaghraby and Keskinocak } \\
\text { (2003) }\end{array}$ & $\begin{array}{l}\text { Dynamic pricing in the presence } \\
\text { of inventory considerations: } \\
\text { research overview, current prac- } \\
\text { tices, and future directions }\end{array}$ & Dynamic \\
\hline & Management Science & Feng (2010) & $\begin{array}{l}\text { Integrating dynamic pricing and } \\
\text { replenishment decisions under } \\
\text { supply capacity uncertainty }\end{array}$ & Dynamic \\
\hline & Operations Research & Song et al. (2009) & $\begin{array}{l}\text { Optimal dynamic joint inventory- } \\
\text { pricing control for multiplica- } \\
\text { tive demand with fixed order } \\
\text { costs and lost sales }\end{array}$ & Dynamic \\
\hline
\end{tabular}

industry have implemented algorithmic pricing approaches (Bouchet et al. 2016; Chen and Chen 2015). Moreover, when it comes to the pricing of professional graduate programs, financial, or insurance products, and services, or information goods, individual prices are already a common practice (Feldman et al. 2015; Waldfogel 2015). With technology firms such as Google, Microsoft, and Amazon, offering algorithmic pricing solutions out of the box, there are no obstacles for the widespread use of the pricing strategy, even for smaller sized companies (Calvano et al. 2019; Xia et al. 2019). In a recent study on the adoption of algorithmic pricing on Amazon Marketplace, it was uncovered that over 500 
Table 3 Personalized pricing: themes with key publications

\begin{tabular}{|c|c|c|c|c|}
\hline Theme/cluster & Journal & Author (year) & Title & $\begin{array}{l}\text { Type of } \\
\text { algorithmic } \\
\text { pricing }\end{array}$ \\
\hline \multirow[t]{4}{*}{ Ethical issues } & Marketing Science & Chen and Iyer (2001) & $\begin{array}{l}\text { Consumer addressability and custom- } \\
\text { ized pricing }\end{array}$ & Personalized \\
\hline & Management Science & Choudhary et al. (2005) & $\begin{array}{l}\text { Personalized pricing and quality dif- } \\
\text { ferentiation }\end{array}$ & Personalized \\
\hline & Journal of Consumer Psychology & Barone and Roy (2010) & $\begin{array}{l}\text { The effect of deal exclusivity on } \\
\text { consumer response to targeted price } \\
\text { promotions: a social identification } \\
\text { perspective }\end{array}$ & Personalized \\
\hline & MIS Quarterly & Koh et al. (2017) & $\begin{array}{l}\text { Is voluntary profiling welfare enhanc- } \\
\text { ing? }\end{array}$ & Personalized \\
\hline \multirow[t]{3}{*}{ Legal issues } & Theoretical Inquiries in Law & Caplan and Stringham (2008) & Privatizing the adjudication of disputes & Personalized \\
\hline & Economics Letters & Zenger (2012) & $\begin{array}{l}\text { The marginal price effects of antitrust } \\
\text { rules against price discrimination }\end{array}$ & Personalized \\
\hline & Journal of Consumer Policy & Zuiderveen (2017) & $\begin{array}{l}\text { Online price discrimination and EU } \\
\text { privacy law }\end{array}$ & Personalized \\
\hline \multirow{4}{*}{$\begin{array}{l}\text { Pricing policies and } \\
\text { personalization } \\
\text { models }\end{array}$} & Operations Research & Aydin and Ziya (2009) & $\begin{array}{l}\text { Personalized dynamic pricing of lim- } \\
\text { ited inventories }\end{array}$ & Personalized \\
\hline & Marketing Science & Rust and Chung (2006) & $\begin{array}{l}\text { Marketing models of service and } \\
\text { relationships }\end{array}$ & Personalized \\
\hline & Management Science & Wu et al. (2008) & $\begin{array}{l}\text { Customized bundle pricing for infor- } \\
\text { mation goods: a non-linear mixed- } \\
\text { integer programming approach }\end{array}$ & Personalized \\
\hline & Management Science & Ray et al. (2005) & $\begin{array}{l}\text { Tailored supply chain decision-making } \\
\text { under price-sensitive stochastic } \\
\text { demand and delivery uncertainty }\end{array}$ & Personalized \\
\hline
\end{tabular}

sellers had adopted an algorithmic pricing approach (Chen 2017; Chen et al. 2016a).

Algorithmic pricing is also migrating into and spreading within the offline world. With recent advancements in camera technology and machine learning, grocery stores and other offline contexts are about to become even larger fields of application. Amazon's "Go" store or the Chinese BingoBox track movements and facial expressions of their customers and can make personalized offerings in the shop (Soo 2017). Similar steps are taken by retailers in the UK and Switzerland, testing other forms of in-store tracking such as beacons, which can offer a level of personalized pricing similar to online shops (Gratwohl 2019; PYMNTS 2018). Consequently, algorithmic pricing is rapidly spreading both online and offline, fueled by technological progress and an unprecedented amount of (personal) data.

\section{Concepts and Definitions}

Algorithmic pricing - in its most recent stage-is a pricing strategy that builds on computer algorithms, which set prices for goods and services dynamically at either the aggregate or individual level. Generally, described as "a sequence of computational steps that transform the input into the output," algorithms are automated tools that solve previously specified problems (Cormen et al. 2009, p. 5). Pricing algorithms process input data about markets and actors, accounting for numerous factors such as competitors' prices, consumer demand, or personal behavior and characteristics (such as gender, age, educational background etc.) to determine the output price in relation to the highest (i.e., profit-maximizing prices) achievable revenue (Cohen 2018; Fisher et al. 2018; Keskin and Zeevi 2014; Zhang 2011). Different use case scenarios require different types of pricing algorithms, which can be broadly categorized as adaptive algorithms (first generation), and learning algorithms (second generation) (Calvano et al. 2019). The levels of complexity may thus range from simple if-then procedures (e.g., if the temperature is above $20{ }^{\circ} \mathrm{C}$, the price of the Coke goes up) to artificial intelligence (AI), machine learning and neuronal networks (Calvano et al. 2019). Recent literature highlights machine learning approaches focusing on behavioral patterns to predict future demand and forecast individual willingness to pay (Ettl et al. 2019; Miklós-Thal and Tucker 2019; Xia et al. 2019). Algorithms that build on reinforcement learning can even further develop on their own when adjusting to changing market conditions, not requiring a programmer to rewrite the underlying code (Calvano et al. 2019; Xia et al. 2019). 
Table 4 Concepts and definitions referring to algorithmic pricing

\begin{tabular}{|c|c|c|}
\hline Author (year) & Title & Concept/definition \\
\hline Calvano et al. (2019, p. 156) & $\begin{array}{l}\text { Algorithmic pricing what implications for competi- } \\
\text { tion policy? }\end{array}$ & $\begin{array}{l}\text { "Firms' pricing decisions are increasingly delegated } \\
\text { to software programs that incorporate the latest } \\
\text { developments of artificial intelligence" }\end{array}$ \\
\hline Bar-Gill (2019, p. 243) & $\begin{array}{l}\text { Algorithmic price discrimination when demand is a } \\
\text { function of both preferences and (mis)perceptions }\end{array}$ & $\begin{array}{l}\text { "Algorithmic price discrimination occurs when sellers } \\
\text { gain information about each consumer's individual } \\
\text { WTP and set a personalized price equal to that } \\
\text { consumer's WTP" } \\
\text { "Fueled by big data, algorithmic price discrimination } \\
\text { enables sellers to parse the population of potential } \\
\text { customers into finer and finer subcategories-each } \\
\text { matched with a different price" }\end{array}$ \\
\hline $\begin{array}{l}\text { UK Competition and Markets } \\
\text { Authority }(2018, \text { p. } 7)\end{array}$ & Pricing algorithms & $\begin{array}{l}\text { "[T]he use of algorithms in firms' pricing decisions, } \\
\text { such as setting the market-wide price or offering } \\
\text { personalised prices to individual consumers" }\end{array}$ \\
\hline Chen et al. (2016a), p. 1339) & $\begin{array}{l}\text { An empirical analysis of algorithmic pricing on } \\
\text { amazon marketplace }\end{array}$ & $\begin{array}{l}\text { "The rise of e-commerce has unlocked practical } \\
\text { applications for algorithmic pricing (sometimes } \\
\text { referred to as dynamic pricing algorithms or Rev- } \\
\text { enue/Yield Management)" }\end{array}$ \\
\hline Oxera Consulting LLP (2017, p. 5) & When algorithms set prices: winners and losers & $\begin{array}{l}\text { "When it comes to price-setting, algorithms are com- } \\
\text { puter programs that set prices in an automated way" }\end{array}$ \\
\hline Karr (2018) & How to use algorithmic pricing to maximize profits & $\begin{array}{l}\text { "Our automatic self-learning algorithms will help you } \\
\text { maximize your profit margins for your private label } \\
\text { products, ultimately accelerating your private label } \\
\text { business growth" }\end{array}$ \\
\hline
\end{tabular}

A wide range application of algorithmic pricing is said to benefit businesses and consumers alike, yet, at the same time, firms excitement is met by consumer concerns (Martin 2019b; Schechner 2017). From a research perspective, discussions on the ethicality of algorithms in general and pricing algorithms in particular are still limited (Elegido 2011, 2015; Martin 2018, 2019a; Mercier-Roy and Mailhot 2019). As outlined by Martin (2018) and Mittelstadt et al. (2016), algorithms are inevitably "value-laden" as opposed to neutral decision tools. Value-laden thereby entails that an algorithm reflects the values of the engineers and users (Mittelstadt et al. 2016). Designing an algorithm value-neutral is practically not feasible, given for example the large size teams that are usually necessary to write the code. As a consequence, the algorithm comes with certain value-judgments baked in that reflect the designers and user preferences for some values over others (Kraemer et al. 2011). Often, the underlying values of an algorithm remain hidden, until a controversy reveals the values embedded in the code.

Regarding the two major types of algorithmic pricing analyzed here, we find both pros and cons from a business and marketing ethics perspective, as well as moral ambiguities. Price discrimination as such does not have to be unfair (Elegido 2011). From an economic and technical perspective, price discrimination represents first and foremost a neutral concept without inherent negative connotations that the common understanding of the word 'discrimination' would suggest (Steppe 2017). However, the reviewed literature indicates that particularly first-degree price discrimination and group-specific price discrimination do, in fact, pose ethical challenges well deserving closer attention from researchers and regulators. Particularly controversies surrounding personalized pricing have revealed hidden values in the code that tend to be perceived as unfair, asymmetric, or even as inhumane (e.g., Uber taxis charging exorbitant fares during terrorist attacks). When price discriminatory effects are perceived as adverse, they may entail adverse consequences for corporations, especially when found to be ethically problematic on close inspection. These ethical challenges of algorithmic pricing arise from data analytic capacities to identify personal and group characteristics that allow for sophisticated behavioral price discrimination (Elmaghraby and Keskinocak 2003).

Given the fundamental novelty of the concept, the search for a comprehensive definition of algorithmic pricing (comprising dynamic and personalized pricing) turned out to be challenging. In reviewing the extant literature, we came across several definitions which differ in their level of clarity and precision. Previous definitions predominantly focus on the technical aspects of the phenomenon which conscribe technical characteristics while leaving ethical considerations aside (Bar-Gill 2019; Calvano et al. 2019; Chen et al. 2016a; UK Competition and Markets Authority 2018). In Table 4 the extant definitions are listed. What becomes clear from the table, there are neither ethically informed definitions, nor definitions relating directly to business and marketing 
ethics, accounting for the challenges involved in algorithmic pricing, as described above. The core themes of existing definitions in Table 4 highlight the role of data which lets automated algorithms divide consumers in fine-grained (sub)categories, up to the assessment of an individual's willingness to pay, to set prices according to a value maximizing function of the firm.

Given the current definitions, we believe there is a need for a more comprehensive definition of algorithmic pricing that builds on the existing research, while accounting for previously omitted ethical considerations. Consequently, we propose the following definition incorporating the ethical dimension:

Algorithmic pricing is a pricing mechanism, based on data analytics, which allows firms to automatically generate dynamic and customer-specific prices in real-time. Algorithmic pricing can go along with different forms of price discrimination (in both a technical and moral sense) between individuals and/or groups. As such, it may be perceived as unethical by consumers and the public, which in turn can adversely affect the firm.

\section{Pricing Algorithms in General}

Broadly defined, an algorithm is a "process or set of rules to be followed in calculations or other problem-solving operations" (Oxford Dictionary 2019). In the context of revenue and yield management, algorithms are used to maximize revenues and profits by calculating the optimal allocation of goods and adapting the prices accordingly. This strategy of using algorithms or software in general to determine prices has been coined "algorithmic pricing" (see, e.g., Calvano et al. 2019). With this tactic, prices can be adapted dynamically according to algorithmic formulas taking complex and volatile market conditions into account.

Algorithmic pricing is used predominantly in domains with limited goods which are short term or perishable (Elmaghraby and Keskinocak 2003; Ettl et al. 2019). The most prominent example is the airline industry with many fluctuating market factors (Brumelle and McGill 1993; van Ryzin and McGill 2000). The tactic of flexibly adapting prices is also increasingly introduced in other domains such as in the e-commerce market or for personalization (Chen et al. 2016a; Ettl et al. 2019).

In the traditional dynamic pricing research, adaptive algorithms for optimization and estimation of prices are used to calculate models in which prices are optimized under varying market conditions, e.g., whether the firm is a monopolist or whether consumers are price-sensitive (Aydin and Ziya 2009; Bitran and Mondschein 1997). Such models use and combine different parameters and algorithms such as stochastic approximation algorithms (Robbins and Monro 1951) and Fibonacci algorithms (see, e.g., Bitran and Mondschein 1997). Others include principles of Bayesian decision theory and apply it to pricing strategies (Green 1963). Another widely used approach is to use different forms of learning algorithms with or without reinforcement learning. These algorithms actively change parameters with respect to varying external conditions. Sub-forms of reinforcement learning algorithms are Q-learning algorithms such as naïve Q-learning, multi-agent Q-learning, zerosum games and MinMax Q-Learning, general-sum games and Nash Q-Learning (Ittoo and Petit 2017). They can, for instance, be used to solve Markov and semi-Markov decision problems (MDP, Gosavi 2004a) ${ }^{4}$ One algorithm from this kind is proposed by Gosavi (2004b). It is a model-free and asynchronous algorithm that applies a nearest-neighbor approach to solve MDP in the pricing context. Other learning algorithms use R-learning (Schwartz 1993) or SMART and Relaxed-SMART algorithms (Das et al. 1999). The latter group of algorithms are all based on some form of value iteration.

Depending on the pricing domain, complexity, and specific requirements of the setting, many different algorithms could theoretically be used to optimally calculate prices and the best performance has to be identified. For example, Ettl et al. (2019) compared the performance of different approximation algorithms for setting the prices of personalized project bundles while similarly taking the inventory management into account. The algorithms tested were, e.g., exponential multiplicative algorithms, separableitem algorithms, myopic heuristic algorithms to name only a few. Therefore, when firms delegate pricing decisions to algorithms as opposed to the traditional approach of defining a specific price for a certain good, this approach of algorithmic pricing can theoretically apply a broad variety of algorithms using several different factors and parameters and integrating different types of algorithms in order to dynamically calculate and adapt prices.

\section{Ethical Issues: Consumer Behavior and Marketing Ethics}

\section{Dynamic Pricing}

Thus far, ethical concerns about dynamic pricing have received only scant attention. The most critical points have been raised about the modeling of pricing policies and potential effects on consumer behavior (Lee and Monroe 2008). In a study of price fairness in relation to dynamic pricing, Haws and Bearden (Haws and Bearden 2006) conclude that

\footnotetext{
4 MDPs are a group of problems in which a decision maker shall find the optimal solution in several states of a system in order to optimize performance metrics.
} 
negative effects can arise when customers become aware of price differences. Consumers typically perceive dynamic pricing as unfair, as soon as the inherent price discrimination is detected (Garbarino and Lee 2003; Haws and Bearden 2006). Price discrimination as such, however, does not necessarily have to be seen as unfair (Elegido 2011). Dynamic pricing can be detected when the stated price substantially differs from an internal or external reference price of the consumer (Garbarino and Lee 2003). Prices can be framed, however, in ways to mitigate such potentially negative perceptions, for instance, by providing external reference prices that make the stated price appear more attractive, or by offering an additional cash coupon or a gift (Lee and Monroe 2008; Weisstein et al. 2013). In online environments, highly popular sites such as Ebates or MrRebates build on cash back models, offering two asymmetric prices thereby making use of promotions and price discrimination at the same time (Ho et al. 2017). Ho et al. (2017, p. 2), warn in this regard from the "cash-back paradox," meaning that "[u]nder some conditions, all consumers will end up suffering from higher prices compared with the uniform price they would have faced if the merchant did not price discriminate."

In response to the increased use of dynamic pricing, some consumers have started to become more strategic in their online shopping behavior (Kremer et al. 2017; Liu and van Ryzin 2008). For instance, they often plan their purchases (Liu and van Ryzin 2008) or check prices and inventory information ex-ante (Cho et al. 2009), to form a strategic response to the dynamic pricing of a firm. Yet, from a consumer perspective, it remains a challenging task to recognize price changes and to make correct predictions about future price developments (Radner et al. 2014). Garbarino and Maxwell (2010) argue that adverse consumer reactions to dynamic pricing, such as lower future purchase intentions, decreased trust, or willingness to complain, are also subject to cultural norms. These authors stress that price discrimination between groups is widely accepted (Garbarino and Maxwell 2010). Dynamic pricing, though, remains only an approximation-a precursor-of what is to be discussed next: personalized pricing building on personal preferences and individual behavior.

\section{Personalized Pricing}

Contrary to dynamic pricing, ethical issues of personalized pricing have triggered a broader public and scholarly debate (see, e.g., Amazon's experiments with personalized pricing as the most publicized negative example in the year 2000, Choe et al. 2018). Personalized pricing goes beyond demand estimations of groups toward the demand of the individual (Obermiller et al. 2012). Digital tracking via 'cookies' and 'digital breadcrumbs' allow firms to analyze consumer behavior data and to decipher personal characteristics and preferences, to implement (almost) perfect price discrimination by identifying a customer's reservation price, the individual willingness to pay (Bitran and Caldentey 2003; Ezrachi and Stucke 2016). What remains invisible for the eye of most consumers, is the fact that their online behavior creates a long data trace consisting of personal characteristics such as location data, browsing and purchasing history, social media posts and 'likes,' and so on (Ayadi et al. 2017). In sum, these personal characteristics allow firms to build fine-grained profiles about individual purchasing preferences, tastes, and habits that often also reveal a customer's income or health status (Steppe 2017). Building on the data, pricing algorithms can estimate consumers' willingness to pay or as Xu and Dukes (2019) state, gain "superior knowledge" by understanding consumer preferences better than themselves. For instance, the knowledge about a consumer's brand preference is being used to charge higher prices (Esteves 2014). Similarly, a low smartphone battery is taken by Uber to indicate that a customer might be more likely to accept a surge price (Dakers 2016). Thus, the key ethical challenge of personalized pricing lies in the accumulation and analysis of individual behavioral data and the power asymmetries that arise between consumers and firms which possess detailed behavioral profiles of them (Hinz et al. 2011; Koh et al. 2017; Martin and Murphy 2017).

Price fairness plays a key role in any pricing system (Xia et al. 2004). Thus, whether or not personalized pricing is seen as discriminatory, lies mainly in the consumer's fairness perception (Elegido (2011). This fairness perception is formed by numerous factors (see, e.g., Richards et al. 2016). In relation to personalized pricing, interpersonal price differences, the perceived violation of social norms, and price framing are particularly relevant. When personalized pricing is unveiled and it is brought to the attention of consumers that they are paying a substantially higher price than their peers, the practice is perceived as unfair or manipulative, and trust, as well as demand, can decrease (Zuiderveen Borgesius and Poort 2017). Similar reactions are triggered, when personalized pricing is supposed to violate social norms, such as charging a lower price to a new customer (Maxwell and Garbarino 2010). Maxwell and Garbarino (2010) caution that this may be culture-dependent, with reference to an Indian delivery service that with apparent impunity charges individuals up to 50\% more if they are located in a wealthy neighborhood. Lastly, price framing is a decisive element whether a price is perceived as fair or not. Several authors demonstrate that firms can successfully counter peer-induced fairness concerns by obfuscating prices to impede interpersonal comparisons and to raise the chances that consumers accept the prices offered (Allender et al. 2016; Gu and Wenzel 2014; Kalaycı 2016). In this manner, personalized prices can be framed as explicit personal offerings, such as 
exclusive deals and are therefore more likely to be accepted (Barone and Roy 2010).

\section{Legal Issues}

\section{Dynamic Pricing}

Dynamic pricing mechanisms have recently moved in the focus of competition law authorities around the globe, given their potential to form illegal price-fixing cartels (Gal 2017, 2019; Schwalbe 2018; Stucke and Ezrachi 2016). Noteworthy in this regard is the Topkins price-fixing case from 2015, where the U.S. Department of Justice prosecuted against an illegal price-fixing cartel that shared dynamic pricing algorithms for the sale of posters on the Amazon Market place (Gal 2019; Stucke and Ezrachi 2016). Competition law generally does not allow "agreements among market players to restrict competition, without offsetting benefits to the public" (Gal 2019, p. 18). Authorities are thus confronted with the question whether existing legal frameworks and tools are sufficient to monitor such algorithmic behavior and enforce competition law in an automated online environment (Schwalbe 2018). Particularly, as recent research has shown that reinforcement learning algorithms may autonomously lead to tacit collusion, blurring the lines to explicit collusion (Ittoo and Petit 2017; Van Uytsel 2018).

\section{Personalized Pricing}

As personalized pricing is expanding into ever more areas of life, it also raises legal questions, particularly with regard to price discrimination and privacy (Koh et al. 2017). Whereas non-linear pricing policies that are universally applied to all customers are usually not in breach of existing law, discriminatory non-linear pricing schemas, such as personalized two-part tariffs, have attracted the attention of anti-discrimination and antitrust law in several countries (Zenger 2012). However, it has been shown that existing law is often inept and even counterproductive when it comes to protecting consumers from potential power asymmetries. In an attempt to improve consumer privacy, the Dutch government issued a law in 2012 requiring website owners to inform users about tracking, profiling and personalization practices before the visit (Helberger 2013). As a result, the majority of websites made use of a 'cookie wall' that allowed the user only to consume the content, if they agreed to the personalized tracking practices, which, in fact, were decisively more invasive than the previous default settings. Regulatory intervention against personal data collection may be counterproductive, only yielding advantages when consumers are naïve, and the market is characterized by limited competition and price discrimination (Hoffmann et al. 2013; Koh et al. 2017).
In relation to online shops, Zuiderveen and Poort (2017) argue that European data protection law applies to personalized pricing insofar as personal data are processed. As online services tend to personalize prices via the usage of cookies for identification, tracking, and categorization of customers, it can be inferred, that the European General Data Protection Regulation applies in most online shop cases. Consequently, a firm that is applying a personalized pricing scheme in the European Union must inform its customers about the purpose of the personal data processing. A practical compromise that bridges the gap between proponents and opponents of personalized pricing in this context is the possibility to "opt-in" to or "opt-out" from personal profiling, which may also serve in contexts where the existing data protection law is limited (Koh et al. 2017).

\section{Pricing Policies and Personalization Models}

\section{Dynamic Pricing}

At the center of most dynamic and personalized pricing schemes stands the principle of profit maximization (Besbes and Zeevi 2015). The objective function of a dynamic pricing policy aims at increasing the overall revenue or profit for a given firm by choosing the optimal price for a good or service (Chen and Gallego 2019). Dynamic pricing policies can be designed in different ways, depending on the variables the policy should take into account. They typically build on differing mathematical approaches, which can be broadly categorized according to Bayesian, (Gallego and Talebian 2012), and non-Bayesian methodologies [see, e.g., RamseyBoiteux, Hamilton-Jacobi-Isaacs (HJI) equation, Taylor's discrete model]. ${ }^{5}$ Generally, these mathematical approaches strive to find an answer to uncertainty problems between the price and expected demand of an item (good/service) in a given period (den Boer 2015), as will be further explained below.

The demand side of a policy equation is typically characterized by fluctuation over time or static demand situations, where the inventory level (see inventory management) causes pricing dynamics. Demand needs to be specified for a certain time horizon (Feng et al. 2015). Products or services are usually time-sensitive, meaning that they can only be sold within a finite selling season,

\footnotetext{
${ }^{5}$ Computational and modeling advancements have paved the way for Bayesian approaches. In marketing, Bayesian hierarchical models go beyond standard hierarchical approaches, allowing for greater flexibility, modularity, and, in essence, give the ability to calculate to what extent any a prior given belief should be revised vis-à-vis new data (Rossi et al. 2012: Bayesian Statistics and Marketing). Thus, Bayesian models make a statement about what can be reasonably assumed about a hypothesis, in light of data.
} 
itself comprised of selling periods (Chen and Chen 2015). Thus, finite time approaches (Levin et al. 2008) can be distinguished from two-period ( $\mathrm{Li}$ et al. 2015b) or multiperiod models (Cohen et al. 2018). Whereas some of the earlier models treated the demand as completely known to the firm, contemporary - and more realistic — approaches consider uncertain demand situations (Besbes and Zeevi 2015) and learning effects on the part of the seller (den Boer 2015). As modern technology and in particular neuronal networks have evolved, more recent dynamic pricing policies can account for multiple scenarios adaptively adjusting to and predicting the behavior of competitors and consumers alike (Calvano et al. 2019; Xia et al. 2019).

\section{Personalized Pricing}

From a corporate perspective, personalized pricing aims at the same objective function as dynamic pricing policies-revenue maximization over the long-run. Similar to dynamic pricing, the mathematical models typically build on Bayesian or game-theoretic approaches (Amaldoss and He 2019). Central to constructing an effective personalized pricing model is the analysis of a customer's individual purchase history or recent behavior (Amaldoss and He 2019). The policies are framed at learning from past and present customer behavior and at turning the acquired information into additional revenue (Amaldoss and $\mathrm{He}$ 2019; Ettl et al. 2019).

Customer information is a valuable revenue source, as it can help firms to identify individual preferences and personalize the price (Choe et al. 2018; Cohen 2018). Equipped with such detailed profiles, firms can, for instance, manipulate customers via personalized emotional pitches to increase their consumption and willingness to accept a certain price (Amaldoss and He 2019; Townley et al. 2017). Contrary to conventional wisdom, lower search costs for prices on the internet do not go along with reduced prices. Chen and Sudhir (2004) outline how personalized pricing can counter lower search costs such that average costs remain high. Firms can use this knowledge and charge high prices for loyal customers and low prices for the price-sensitive segments (Chen and Sudhir 2004). A noteworthy moderator for the effectiveness of personalized pricing is the customers' permission to allow firms to collect data and send personalized offers, such as emails (Chen and Sudhir 2004). In the market for smartphone applications, the trade-off between low prices and more privacy is also becoming increasingly important, as apps are offered at low prices, when customers confirm with the collection of personal data (Kummer and Schulte 2019). Overall, consumer welfare can increase, although, privacy-sensitive consumers may be left out of the market (Chen and Sudhir 2004; Kummer and Schulte 2019).

\section{Inventory Management}

Pricing policies can also substantially vary based on the context they are used in. Inventory management is a critical business function for many firms, given that marginal improvements can lead to substantial savings (Tan et al. 2017). In short, an inventory-based dynamic pricing policy needs to correspond with ordering and supply decisions, production control and safety stock to hedge potential demand uncertainty ( $\mathrm{Li}$ et al. 2015a). The limited life cycle of the products, fluctuating procurement costs, and demand uncertainty are some of the key issues in this regard (Xiao et al. 2015). Dynamic pricing is an instrument to manage and control inventory efficiently and to react to market demand at the same time (Li et al. 2015a). Traditionally, prices for an item can be increased, when the inventory decreases. Contrary, once a product is overstocked, price discounts (e.g., fire sales) can trigger a reduction in stock (Dilmé and Li 2019). Appropriate inventory levels are critical when a firm wants to utilize the benefits of dynamic pricing as costs for holding inventory are usually substantial and the question, whether or not a product can be replenished, are important aspects to consider (Chen and Chen 2015; Huang et al. 2014). Thus, firms are often faced with a trade-off between overstocking and understocking applying markdown programs or low pricing strategies as a way to balance the two sides (Huang et al. 2014; Özer and Zheng 2016; Zhang et al. 2019). Overstocking, sometimes referred to as 'inventory waste,' creates costs for holding inventory and accounts for lost sales (Huang et al. 2014; Tan et al. 2017). In this regard, Liu and Van Ryzin (2008) analyze deliberate understocking, which creates rationing risk and is bound to incentivize buyers to purchase earlier and at higher prices. However, Adida and Özer (2019) highlight that potential stockouts can risk consumer regret. Thus, frequency and depth discounting or the more uncommon everyday low pricing modalities are ways to handle over and understocking (Adida and Özer 2019; Danziger et al. 2014).

\section{Demand Uncertainty and Algorithms}

An increasing amount of literature deals with uncertain demand situations (see, e.g., Besbes and Sauré 2014). Moreover, strategic consumers might anticipate a pricing strategy and postpone a purchase, waiting for lower future prices (Zhou and Chao 2014). Thus, firms are often faced with a trade-off between generating revenues from current demand while accounting for unknown prospective demand (Besbes and Sauré 2014). Adaptive dynamic pricing algorithms help firms to deal with this demand uncertainty. They can learn 'on the fly' and optimize pricing accordingly. Dynamic pricing algorithms can be designed in different ways, for example, by building on heuristic models (Bront et al. 2009) 
Table 5 Overview of ethical assessment on micro, meso, and macro levels

\begin{tabular}{|c|c|c|c|}
\hline & Good & $\mathrm{Bad}$ & Ambivalent \\
\hline Micro & $\begin{array}{l}\text { Possible gain in consumer surplus } \\
\text { Psychological rewards from bargain } \\
\text { hunting (price surprise, price emotion) } \\
\text { Enhanced personalized services }\end{array}$ & $\begin{array}{l}\text { Possible loss in consumer surplus }{ }^{\mathrm{a}} \\
\text { Privacy loss }^{\mathrm{a}} \\
\text { Potentially higher prices for consumers } \\
\text { Decrease in price certainty and thus, low planning } \\
\text { security and uncertainty for consumers } \\
\text { Lower price transparency } \\
\text { Increase in price complexity }\end{array}$ & $\begin{array}{l}\text { Surge pricing }^{\mathrm{a}} \\
\text { Focus on price only } \\
\text { Perceived fairness und control }^{\mathrm{a}} \\
\text { Eroding trust }\end{array}$ \\
\hline Meso & $\begin{array}{l}\text { Relative increase in revenue and profit } \\
\text { Possible increase in profits (at fiscal level) } \\
\text { Utilization optimization } \\
\text { Fewer waste of resources }\end{array}$ & $\begin{array}{l}\text { Higher operational requirements (IT investment) } \\
\text { Erosion of price image } \\
\text { Loyalty challenged } \\
\text { Difficulty to plan on the corporate and civil society } \\
\text { level }\end{array}$ & $\begin{array}{l}\text { Increase in competition? Race } \\
\text { to the bottom (price war) } \\
\text { Short term Profit vs. long term } \\
\text { customer relation } \\
\text { More difficult to defend premium } \\
\text { prices for products which } \\
\text { are socially and ecologically } \\
\text { sustainable? } \\
\text { Trend toward segmentarization } \\
\text { of prices? Eligibility of price/ } \\
\text { service elements? }\end{array}$ \\
\hline Macro & $\begin{array}{l}\text { Reduction in global footprints through } \\
\text { more efficient capacity utilization } \\
\text { Higher quality of life through increased } \\
\text { access to goods and services } \\
\text { Higher profits (and taxes) }\end{array}$ & $\begin{array}{l}\text { Undermines human rights of non-discrimination } \\
\text { (gender, age, health, status) } \\
\text { Increased externalities through market growth } \\
\text { Higher societal costs and stress though more intense } \\
\text { competition in labor markets } \\
\text { Increase in price wars enforces shift from value to price } \\
\text { in societal communication about goods and services }\end{array}$ & $\begin{array}{l}\text { Securing employment/potential } \\
\text { job losses } \\
\text { Customization of products and } \\
\text { services enhanced in tandem } \\
\text { with increased dynamism of } \\
\text { prices? }\end{array}$ \\
\hline
\end{tabular}

Topics discussed are highlighted in bold, topics omitted in italics

${ }^{a}$ Elements marked with an asterisk are largely related to personalized pricing

or by taking 'hybrid' forms (Xiong et al. 2010), depending on the demand type, they are meant to decipher and predict. Some make direct use of emerging demand data or learn from historical sales pricing and inventory decisions and can also serve as a decision tool for risk-averse mangers (Cohen et al. 2018).

\section{Mapping the Micro, Meso, and Macro Levels of Algorithmic Pricing}

The relevance of algorithmic pricing to business and marketing ethics stems from its centrality to business in market economies. In terms of microeconomics, prices are said to have the function of steering firms to produce what customers are most willing to pay for, thereby prompting them to reduce scarcity in the very goods and services that people want dearest. At the same time, firms will use prices (and the scarcity of resources that they communicate) for monitoring their costs, which, in terms of macroeconomics, leads them to employ resources with thrift and ingenuity. As a result, unregulated prices are central to two conventional legitimations of market economies: They allow-or so the story goes-for individual economic freedom while at the same time assuring that this freedom, coupled with rational maximization behavior, leads to the overall most efficient use of societal resources. Given this pivotal economic role, any substantial change in the way how prices are set is bound to be of significance from a business and marketing ethics perspective; especially when decisions on pricing are automated via algorithms and do not require human input anymore (Angel and McCabe 2018; Miklós-Thal and Tucker 2019).

In the following analysis, we build on a social sciences approach rooted in evolutionary economics to outline the ethical challenges connected to algorithmic pricing for the micro, meso, and macro levels of society (Dopfer et al. 2004). The strength of this analytical framework lies in differentiating between individual (micro level) and aggregated population perspectives (macro level), whereby organizations and structures are represented by the intermediary trajectory (meso level) that connects and affects both the micro and macro levels. In our ethical assessment of algorithmic pricing that is to follow, we draw on major streams of ethical thinking, namely deontology, teleological and consequentialist ethics, social contract theory, and utilitarianism to mark and classify instances where algorithmic pricing would surely be approved (moral goods), or rejected (moral bads) by most ethical schools (for a similar approach in a different context see Dierksmeier and Seele 2016). In a third category 
Table 6 Micro level: ethical assessment with example articles

\begin{tabular}{lllll}
\hline Ethical assessment & Topic & Author (year) & Title & $\begin{array}{c}\text { Type of } \\
\text { algorithmic } \\
\text { pricing }\end{array}$ \\
\hline Good & Consumer surplus & Chen and Gallego (2019) & Welfare analysis of dynamic pricing & $\begin{array}{l}\text { Dynamic } \\
\text { Bad }\end{array}$ \\
& Behavioral discrimination & Ezrachi and Stucke (2016) & The rise of behavioral discrimination & Fersonalized \\
Ambivalent & Privacy loss & Helberger (2013) & $\begin{array}{l}\text { Freedom of expression and the Dutch Cookie-Wall } \\
\text { Personalized } \\
\text { offects of price framing on consumers' perceptions }\end{array}$ & Dynamic \\
\hline
\end{tabular}

(moral ambiguities), we gather those instances where the ethical evaluation varies according to the moral perspective and does not allow for an unequivocal ethical classification. Applying this categorization to the micro, macro, and meso levels, we can derive a heuristical matrix that provides a structured overview and permits for identifying critical research gaps and future challenges related to algorithmic pricing (see Table 5).

\section{The Micro Level ${ }^{6}$}

\section{Moral Goods: Consumer Surplus}

Public opinion suggests that corporations are profiting from algorithmic pricing at the expense of consumers. With this in mind, firms are often reluctant to introduce a dynamic or personalized pricing scheme. Chen and Gallego (2019) reveal that the consumer backlash or negative press is not necessarily substantiated given that not only firms but also consumers can benefit. The outcomes may range from lower market prices to positive consumer responses and an increase in consumer surplus (Faruqui and Palmer 2011). Additionally, on a psychological level, dynamic or personalized pricing can hold rewards for those looking for a bargain (price surprise) and increased customer satisfaction, when the algorithmic pricing policy goes along with an increase in the quality of the product or enhanced personalized services (Choe and Wu 2015; Rayna et al. 2015). Given that potential consumer gains are threatened by personalized pricing policies that may increase corporate profits by capturing a larger share of the consumer surplus, the assessment as to whether dynamic pricing helps or hinders customer satisfaction needs to be made on a case-by-case basis. Table 6 provides an overview of the ethical assessment on the micro level, highlighting a selection of key topics and articles.

\footnotetext{
${ }^{6}$ It is important to note that discussions on the ethicality of algorithmic pricing on the micro level are predicated on the general moral acceptance of the overlying levels. A rejection of the free market foundations and the value maximizing precept would render ethicality discussion on the micro level obsolete.
}

\section{Moral Bads: First-Degree Price Discrimination}

First-degree price discrimination or so-called perfect price discrimination increases the firms' benefits by skimming consumer surplus. In a data-driven economy, first-degree price discrimination evolved from a theoretical concept to real-world practice. To be successfully applied, it is necessary to estimate with sufficient accuracy the consumer's reservation price-the maximum price a person is willing to pay for a given unit-and to install an individual negotiation process between the consumer and the seller. In the past, high negotiation costs, as well as limited knowledge about consumers typically outweighed the potential benefits of first-degree price discrimination. New technologies help firms to get closer to that theoretical construct. At the same time, Ezrachi and Stucke (2016) warn about the increasing personalization and the rise of behavioral discrimination driven by algorithms. Self-learning algorithms build on consumer data so as to recognize patterns which reveal the price-sensitivity or willpower, amongst other individual details (Ezrachi and Stucke 2016). Thus, a consumer's reservation price can be predicted and iteratively refined through novel observations to increase the prediction accuracy and adjust future prices. In a recent example, the British Digital Minister Margot James condemned some airlines for the use of "exploitive" algorithms to identify passengers traveling together and splitting them up, if they do not pay additionally for being seated together (Coffey 2018). Increasing consumer data on the corporate site thus goes along with decreasing anonymity of the individual. Online and offline tracking, profiling, and personalizing is becoming ubiquitous, leaving less and less room for consumers' privacy (Kummer and Schulte 2019; Lee et al. 2011). Since such intrusiveness is unwelcome to customers, many companies mask this feature of their sophisticated and opaque algorithmic pricing structures with lengthy privacy disclaimers. Further, the decrease in price certainty and the concomitant erosion of the price image lead to lower planning security on the micro, but also on the meso and macro levels of society.

Overall, the average consumer remains unaware that personal behavioral characteristics are logged and analyzed allow for prediction of, for example, income and health 
status, and give detailed insights into habits, preferences, and tastes. As a consequence, pricing algorithms can employ the firm's informational advantage and silently sort consumers into segments so as to offer individual prices based on factors that remain opaque to the individual.

\section{Moral Ambiguities: Fairness and Surge Pricing}

Is it fair to charge a different price for the same product? Price fairness rests in part on the consumers' assessment of a given price in relation to the price of a comparative party, such that a difference or lack thereof is judged whether the price is justified, reasonable, and acceptable (Xia et al. 2004). What is perceived as fair in one context might be judged differently in another; and algorithmic pricing literature reveals that price framing tactics can mitigate the (un) fairness perception and thus the customer's level of trust towards a firm (Haws and Bearden 2006; Lee and Monroe 2008; Weisstein et al. 2013). Particularly targeted coupons shown as form of discount are known to be an effective framing tactic, masking personalized pricing (Tanner 2014). The ethical challenge lies in assessing the quality of such price framing tactics and in evaluating whether or to what extent they are used to mislead or manipulate the consumer.

Also resisting a clear-cut good or bad classification are surge prices. Surge prices are the algorithmic response to a rapid demand increase, representing the logic of equilibria building in a market. From a libertarian perspective, there is nothing wrong about this technology, as demand determines supply and customers are at liberty to reject the firms' offers. Uber's surge pricing during hostage and terror situations, highlights, however, that adverse externalities for individuals may arise (Cox 2017; Decker and Saitto 2014). Customers may come to rely on a certain service, only to then be faced with almost prohibitively expensive prices so as to end with the equally unattractive options of either foregoing an essential service or paying an exorbitant price. This phenomenon is also described as acquisition and transaction utility stemming from monetary value of the transaction object and particularly the psychological value of a deal (Thaler 1985). Even if the eventual consumer decision will be voluntary (in a libertarian sense), many may no longer consider it free (in a more quotidian sense of the term). Given that the protection and enhancement of economic freedom, however, is key for the legitimation of market societies, this observation could herald the beginning of a broader debate as to whether the state could or should intervene in algorithmic markets in an ordoliberal sense in order to protect the autonomy of individuals and society at large? Ought not the "quantitative freedom" of certain forms of commerce at times be restricted in the interest of the "qualitative freedom" of all (Dierksmeier 2016, 2018)?

\section{The Meso Level}

\section{Moral Goods: Revenue and Profit Increase Along with Efficiency Gains}

The literature corroborates a high potential for revenue and profit increases on the firm level (Fisher et al. 2018; Waldfogel 2015). In a perfectly competitive environment, these gains would be passed on to consumers eventually. But even where in real-life contexts this effect is merely ephemeral, some of these benefits are still likely to extend beyond the firm by way of rising tax revenues for local and state governments. For that reason alone, algorithmic pricing policies are certainly more than merely a corporate revenue maximization tool.

Firms can also benefit from enhanced control over their service and product sales and gain from cost savings and reduced resource waste. Faruqui et al. (2009) show that electricity corporations can improve their economic efficiency and reduce peak capacities. Similarly, Huang et al. (2014) stress the potential for cost reduction related to inventory holding and possible waste reduction, which is a particular concern for perishable products that could end up as waste if not sold in time. Here again, wider pro-social effects can be appreciated.

Of course, enhancing price efficiency can be considered as an unmitigated good only if the ethicality of efficient market mechanisms as such is accepted as a premise rather than rejected, say, because of the inequalities of income distribution that often go along with such processes. For our purposes here, this debate is, however, tangential, insofar as it should suffice to say that given the acceptance of the premise of efficient markets as moral goods, any further advance in said efficiency should be valued positively. Table 7 provides an overview of the ethical assessment on the meso level, highlighting a selection of key topics and articles.

\section{Moral Bads: Switching Costs and New Operational Costs}

Potential revenue and profit gains, as well as the assumption that adaptation costs are low, make algorithmic pricing very appealing for many firms (Matsumura and Matsushima 2015). Bergen et al. (2003) call this the 'myth of costless price changes,' which overlooks the necessity of an in-depth assessment of customers, the supply chain, and firm structures, before any new pricing policy can be rolled out. Within the organization, physical costs incur related to the installation and maintenance of IT infrastructure. The electricity sector is a suitable example in this regard, showing that investments in smart metering and IT systems can in fact be astronomic (Faruqui and Sergici 2010). Moreover, managerial costs arise through information collection, decision-making, and the communication of a new pricing 
Table 7 Meso level: ethical assessment with example articles

\begin{tabular}{|c|c|c|c|c|}
\hline Ethical assessment & Topic & Author (year) & Title & $\begin{array}{l}\text { Type of } \\
\text { algorithmic } \\
\text { pricing }\end{array}$ \\
\hline Good & Revenue and profit increase & Fisher et al. (2018) & $\begin{array}{l}\text { Competition-based dynamic pricing in online retail- } \\
\text { ing: a methodology validated with field experi- } \\
\text { ments }\end{array}$ & Dynamic \\
\hline Bad & High operational requirements & Bergen et al. (2003) & $\begin{array}{l}\text { Shattering the myth of costless price changes: } \\
\text { emerging perspectives on dynamic pricing }\end{array}$ & Dynamic \\
\hline Ambivalent & Increased competition & Chen and Chen (2015) & $\begin{array}{l}\text { Recent developments in dynamic pricing research: } \\
\text { multiple products, competition, and limited } \\
\text { demand information }\end{array}$ & Dynamic \\
\hline
\end{tabular}

policy (Bergen et al. 2003). Customers, suppliers, and the competitive environment need to be continuously analyzed and evaluated to uphold optimal outcomes for the firm. From a corporate perspective, these vast investments are detrimental whenever they do not lead to the desired outcome in the long-run-and from a macro level perspective the selfsame result would appear as objectionable on account of the negative cost/benefit-ratio in terms of societal inputs and opportunity costs versus (insufficient) pro-social outcomes.

\section{Moral Ambiguities: Competition and Price Wars}

Opponents of algorithmic pricing warn against a potential race to the bottom or a 'price war,' in which firms compete for customers by automatically lowering prices to outperform their competitors, creating a vicious cycle of undercutting. Free market advocates, on the contrary, will argue that open competition and the widespread use of non-static pricing policies are beneficial to customers, given that the increased access to goods and services may lead to an overall higher quality of life (Chen and Gallego 2019). The ambiguity here is both on the descriptive and on the normative front. It is unclear what really will be the long-term effects of a broad employment of algorithmic pricing (descriptively), and how to evaluate (normatively) these effects in light of varying ethical criteria. For example, if a higher degree of material comforts can be had for lower prices but, at the same time, only at the cost of increased insecurity and anxiety on part of customers, adherents of different moral schools of thought may well come to diverging assessments. Social contract theorists might end up welcoming such a development, for instance, whereas virtue ethicists would rather tend to deplore such a result. Utilitarians would ponder the commensurability (or lack thereof) of personal sentiments and interpersonal bargains, whereas deontologists might try to tease out which algorithmic pricing mechanisms, if any, meet suitable standards of universalization such that their employment could be endorsed by all those affected by them.

\section{The Macro Level}

\section{Moral Goods: Reduction in Global Footprints}

Firms' efficiency gains on the meso level can reduce carbon footprints benefitting societies at large. Studies by Faruqui and Sergici $(2010,2013)$ show that households respond to time-of-use pricing, lowering their demand during peak times when prices are dynamically raised. Thus, the problem of over and under consumption can be more successfully managed, thereby lowering the need for additional infrastructures, such as combustion turbines (Faruqui and Palmer 2011). When it comes to the reduction of food waste, the start-up Wasteless provides a dynamic pricing algorithm for supermarkets, which sets prices dynamically based on the product expiry date (Rochelle 2019). The practical application of the algorithm by a Spanish retailer let to a food waste reduction of one-third, while increasing revenues by 6.3\% (Rochelle 2019). Additionally, Wolak (2016) outlines pathways for non-linear pricing plans for water utilities that are linked to demand variations and demographic household characteristics, helping to achieve revenue along with water conservation goals to the benefit of society and the environment; an outcome that virtually all ethical schools would endorse. Table 8 provides an overview of the ethical assessment on the macro level, highlighting a selection of key topics and articles.

\section{Moral Bads: Algorithmic Discrimination of Specific Groups}

With the growth and availability of consumer data, firms can target consumer groups and individuals with increased precision. Based on the input data, modern pricing algorithms achieve high accuracy in market segmentation such that distinct customer groups are served with specific prices (Chen and Chen 2015). This practice bears the risk of treating certain consumer groups less favorably. Algorithmic price segments directly or indirectly reflect customer demographics (Chen and Chen 2015; Ettl et al. 2019; Huang 2010). As a result, 
Table 8 Macro level: ethical assessment with example articles

\begin{tabular}{|c|c|c|c|c|}
\hline Ethical assessment & Topic & Author (year) & Title & $\begin{array}{l}\text { Type of } \\
\text { algorithmic } \\
\text { pricing }\end{array}$ \\
\hline Good & Reduction in global footprints & Faruqui and Sergici (2013) & $\begin{array}{l}\text { Arcturus: international evidence on dynamic } \\
\text { pricing }\end{array}$ & Dynamic \\
\hline \multirow[t]{2}{*}{$\mathrm{Bad}$} & \multirow[t]{2}{*}{ Algorithmic discrimination } & Huang (2010) & $\begin{array}{l}\text { Equilibrium market segmentation for targeted } \\
\text { pricing based on customer characteristics }\end{array}$ & Personalized \\
\hline & & Bock (2016) & $\begin{array}{l}\text { Preserve personal freedom in networked socie- } \\
\text { ties }\end{array}$ & Personalized \\
\hline Ambivalent & Employment & Chen and Sheldon (2016) & $\begin{array}{l}\text { Dynamic pricing in a labor market: surge pric- } \\
\text { ing and flexible work on the Uber platform }\end{array}$ & Dynamic \\
\hline
\end{tabular}

the generated price can particularly disfavor minorities and disadvantaged groups. Algorithmic discrimination based on gender, ethnicity, level of education, wealth, or disability might not be readily apparent or purposefully coded, but the result of (biased) machine learning, arising even without bad intention on part of programmers or firms (Bock 2016). As a consequence, Bock (2016) argues for strong anti-discrimination laws to counter such practices and to guarantee personal freedom in a digitalized market place. This is well in line with the standard schools of business ethics which all concur in denouncing such types of discrimination.

\section{Moral Ambiguities: Employment Opportunities and Challenges}

A fundamental question whether algorithmic pricing will find widespread social acceptance lies in its prospective consequences for the labor market. A common argument holds that the widespread application of algorithmic pricing will destroy jobs and lead to higher societal costs, such as stress, due to an increase in competition and intensity of the labor market. While these predictions might be accurate to a certain extent, future flexible labor markets - in particular, the sharing economy - could also benefit from algorithmic pricing and increased customization of products and services and the possibility of workers to switch to other tasks (Chen and Sheldon 2016). More profound attention is thus necessary to study the way in which dynamic and personalized pricing might impinge upon the labor force and society at large. In other words, job losses in one place might be balanced out, or not, by the creation of new employment opportunities in another.

\section{Conclusion}

\section{Pathways for Future Research}

Only time can tell whether algorithmic pricing will live up to all that it is made out to be. What we can do at this point already, though, is balance the promised benefits against the foreseeable detractions of the technology. On the upside, we note cost savings and revenue gains on the micro, meso, and macro level as quantitatively more and qualitatively finer honed equilibria between supply and demand can be accomplished. Along with these better calibrated deals comes a decrease in waste of the resources and time employed in producing, marketing, and storing wares. Not only customers and firms, but also society and environment, stand to benefit from this effect.

Yet, material gains in terms of efficiency and choice may well come at an immaterial cost. While the downsides of dynamic and personalized pricing cannot necessarily be as easily quantified as its upsides, it seems clear that the increased amount and specification of private choice brought along by algorithmic pricing changes the matrix of individual and institutional decision-making: stress, uncertainty, ambivalence, the feeling of having been duped or snubbed are sentiments that more often than not will go along with the novel technologies. As a result, enhancing the quantitative freedom of many may come at a loss of the qualitative freedom of all (Dierksmeier 2018). Depending on which school of thought one embraces, this observation will lead to contrary evaluations.

Utilitarians and contractarians might be prone to give the new technology their blessings thanks to the greater efficiency and the larger realm of choice that it affords. Deontologists and virtue ethicists might beg to differ. Their focus on the intrinsic rather than instrumental nature of the inputs as well as the outputs of market transactions suggests a more complicated view. As to the inputs, deontologists would question whether economic freedom can be reduced to customer choice, whereas virtue theorists would ponder how each particular choice contributes, or not, to the development of character. As to the outputs, deontologists cannot merely look to aggregate increases in efficiency and material well-being but must scrutinize the distribution of these effects from the perspective of person-specific justice. Similarly, virtue 
ethicists will examine the allocation of the prosperity gains with a view to their contribution to personal flourishing. From either perspective, the endorsement of algorithmic pricing may thus be much more cautious than from the aforementioned schools.

On a broader level, future research may need to reconnect to debates on justice and fairness in pricing (Elegido 2009; Monsalve 2014). If a fair price of a good or service is one equal to its value (Elegido 2015), how can such value equivalence be discerned in the age of algorithmic pricing? Moreover, the current market price might not always be fair. In light of surge pricing, as in the example of Uber and the terrorist attacks in London (Cox 2017), future research may revisit literature on price gouging (Snyder 2012; Zwolinski 2008, 2009). Current pricing algorithms but also the organizations that are using them, appear to be unprepared when it comes to emergency situations or natural disasters that trigger sudden demand peaks. How do pricing algorithms account for the unforeseen and how can companies avoid potential public outcry?

Another field of engagement awaiting further discussion is the ambit of privacy. Through highly personalized information gathering and by way of the individualized nudges that such data sets allow for, algorithmic pricing can be quite an invasive technology. Schools of thought that pride themselves for defending private freedom from outward intrusion, such as libertarians and contractarians, should find this problematic. Deontologists might join them in this assessment, especially when the respective information is garnered stealthily or in a way that, for all practical purposes, customers cannot evade. Other camps of thought, notably those that have forever been skeptical of an all-too-schematic private/public-bifurcation, such as utilitarians and the virtue ethicists, might instead concentrate their assessment on the practical consequences of the employment of nudges based on personalized data. Thus, future research may follow-up on algorithmic memory and the right to be forgotten, which is also an important aspect to consider for algorithmic pricing (Esposito 2017).

As these precursory remarks show, there is a great need for further ethical reflection on algorithmic pricing. At present, the entire realm of pertinent issues cannot yet be conscribed and so our brief list of normative controversies must necessarily be incomplete. What we do hope, though, is that having pointed out these controversial assessments, we have indirectly provided an additional argument for what we stated directly at the outset of this paper, i.e., that it is high time that business and marketing ethicists pay more attention to the realities and future potentialities of algorithmic pricing.

\section{Practical Implications}

As computer technologies rapidly evolve, so are pricing algorithms independently deciding over prices. Decisions made by pricing algorithms are often invisible, outpacing any human actor and carry intentional or unintentional consequences; thus, the notion of algorithmic accountability is becoming increasingly important for firms, managers, and the public (Martin 2018; Mittelstadt et al. 2016). Johnson (2015) highlights this issue, calling it the responsibility gap that may arise when an artificial agent, such as an algorithm takes on roles and makes decisions independently and without direct human control.

In cases where an algorithmic decision leads to markedly adverse outcome for consumers, questions about corporate responsibility are asked, and how to avoid such adverse effects in the future (Cox 2017). Consequently, there have been calls for algorithmic transparency starting from the design process, which could lead to increased accountability (de Laat 2018; Martin 2018; Zerilli et al. 2018). In this regard, the call to publish all algorithms after a certain period-just as is already the case with patentsmight come to mind (Helbing and Seele 2018). Yet, such an approach would reveal potential algorithmic misconduct only years after its occurrence, if at all. Moreover, such approaches in relation to pricing algorithms run contrary to current market logics and firm policies, closely guarding the "secret recipes." Further practical issues may also arise in this regard. A programmer designing the algorithm, and the company selling it, might neither know the exact data the algorithm processes nor can they fully control the output (Esposito 2017). Additionally, an algorithm responsible for some form of misconduct cannot be questioned like a human person; likewise, from a technical point of view, secondgeneration algorithms that build on reinforcement learning, can individually develop their code such that their developers might not even be able to decipher how the algorithm arrived at a certain decision (Calvano et al. 2019; Xia et al. 2019). Thus, the disclosure of the code of pricing algorithms might not be very helpful and from a consumer point of view very difficult to interpret. Not to mention, it will not give consumers insights in the way in which the algorithm is using (personal) data and how it arrived at given prices.

On the downside, an all-encompassing regulation or direct prohibition against adverse effects of pricing algorithms, might neither be feasible or miss the target in a society that has already become algorithm dependent (Bar-Gill 2019; Zerilli et al. 2018). Thus, practitioners need to consider proactive approaches of giving consumers and authorities in supervising authorities the possibility to inspect algorithms and their use of personal data in situ, such that an impact based assessment becomes possible. Such algorithmic auditing might go along with an algorithm certification 
system as well as a certification of algorithm developers, taking codes of ethics into account (Béranger 2018). In this regard, there might be a need for staffing algorithm development teams with representatives of society, and/or implementing an ethics board for oversight (Martin 2018, 2019a). To avoid negative press, consumer backslash or legal consequences, companies could also think of a proactive forms of algorithmic reporting (similar to CSR reporting), providing information that explains the types of algorithms they use and the kind of tasks they are supposed to perform. Particularly competition authorities will be increasingly interested in monitoring such information against the background of algorithmic price fixing and spontaneous or tacit collusion (Gal 2019).

Acknowledgements The authors acknowledge the contribution of 1000 Euro from the research committee (FoKo) of the University of Lucerne, Switzerland, to make this article available as Open Access.

\section{Compliance with Ethical Standards}

Conflict of interest The authors declare that they have no conflict of interest.

Ethical Approval This article does not contain any studies with human participants performed by any of the authors.

Open Access This article is licensed under a Creative Commons Attribution 4.0 International License, which permits use, sharing, adaptation, distribution and reproduction in any medium or format, as long as you give appropriate credit to the original author(s) and the source, provide a link to the Creative Commons licence, and indicate if changes were made. The images or other third party material in this article are included in the article's Creative Commons licence, unless indicated otherwise in a credit line to the material. If material is not included in the article's Creative Commons licence and your intended use is not permitted by statutory regulation or exceeds the permitted use, you will need to obtain permission directly from the copyright holder. To view a copy of this licence, visit http://creativecommons.org/licenses/by/4.0/.

\section{References}

Adida, E., \& Özer, Ö. (2019). Why markdown as a pricing modality? Management Science, 65(5), 2161-2178. https://doi.org/10.1287/ mnsc.2018.3046.

Ajorlou, A., Jadbabaie, A., \& Kakhbod, A. (2018). Dynamic pricing in social networks: The word-of-mouth effect. Management Science, 64(2), 971-979. https://doi.org/10.1287/mnsc.2016.2657.

Allender, W. J., Liaukonyte, J., \& Richards, T. J. (2016). Strategic obfuscation and price fairness. SSRN Electronic Journal. https ://doi.org/10.2139/ssrn.2780170.

Amaldoss, W., \& He, C. (2019). The charm of behavior-based pricing: When consumers' taste is diverse and the consideration set is limited. Journal of Marketing Research, 56(5), 767-790. https ://doi.org/10.1177/0022243719834945.

Angel, J. J., \& McCabe, D. M. (2018). Insider trading 2.0? The ethics of information sales. Journal of Business Ethics, 147(4), 747760. https://doi.org/10.1007/s10551-016-3391-4.
Araman, V. F., \& Caldentey, R. (2009). Dynamic pricing for nonperishable products with demand learning. Operations Research, 57(5), 1169-1188. https://doi.org/10.1287/opre.1090.0725.

Aviv, Y., \& Vulcano, G. (2012). Dynamic list pricing. The Oxford handbook of pricing management. Oxford: Oxford University Press. https://doi.org/10.1093/oxfordhb/9780199543175.013.0023.

Ayadi, N., Paraschiv, C., \& Rousset, X. (2017). Online dynamic pricing and consumer-perceived ethicality: Synthesis and future research. Recherche et Applications en Marketing (English Edition), 32(3), 49-70. https://doi.org/10.1177/2051570717702592.

Aydin, G., \& Ziya, S. (2009). Technical note: Personalized dynamic pricing of limited inventories. Operations Research, 57(6), 1523 1531. https://doi.org/10.1287/opre.1090.0701.

Balmaceda, F., \& Soruco, P. (2008). Asymmetric dynamic pricing in a local gasoline retail market. Journal of Industrial Economics, 56(3), 629-653. https://doi.org/10.1111/j.1467-6451.2008.00349 .X.

Bar-Gill, O. (2019). Algorithmic price discrimination when demand is a function of both preferences and (mis)perceptions. The University of Chicago Law Review, 86(2), 217-254. https:// lawreview.uchicago.edu/publication/algorithmic-price-discr imination-when-demand-function-both-preferences-and.

Barone, M. J., \& Roy, T. (2010). The effect of deal exclusivity on consumer response to targeted price promotions: A social identification perspective. Journal of Consumer Psychology, 20(1), 78-89. https://doi.org/10.1016/j.jcps.2009.10.002.

Belobaba, P. P. (1987a). Air travel demand and airline seat inventory management. Working Paper/Dissertation. Ph.D. dissertation. Cambridge, MA : Flight Transportation Laboratory, Massachusetts Institute of Technology. Retrieved from https://dspac e.mit.edu/handle/1721.1/68077.

Belobaba, P. P. (1987b). Survey paper: Airline yield management an overview of seat inventory control. Transportation Science, 21(2), 63-73. https://doi.org/10.1287/trsc.21.2.63.

Belobaba, P. P. (1989). OR practice: Application of a probabilistic decision model to airline seat inventory control. Operations Research, 37(2), 183-197. https://doi.org/10.1287/ opre.37.2.183.

Béranger, J. (2018). The algorithmic code of ethics: Ethics at bedside of digital revolution. London and Hoboken: Wiley.

Bergemann, D., \& Välimäki, J. (2006). Dynamic pricing of new experience goods. Journal of Political Economy, 114(4), 713-743. https://doi.org/10.1086/506923.

Bergen, M., Ritson, M., Dutta, S., Levy, D., \& Zbarachi, M. (2003). Shattering the myth of costless price changes. European Management Journal, 21(6), 663-669. https://doi.org/10.1016/j. emj.2003.09.018.

Besbes, O., \& Sauré, D. (2014). Dynamic pricing strategies in the presence of demand shifts. Manufacturing \& Service Operations Management, 16(4), 513-528. https://doi.org/10.1287/ msom.2014.0489.

Besbes, O., \& Zeevi, A. (2009). Dynamic pricing without knowing the demand function: Risk bounds and near-optimal algorithms. Operations Research, 57(6), 1407-1420. https://doi.org/10.1287/ opre.1080.0640.

Besbes, O., \& Zeevi, A. (2015). On the (surprising) sufficiency of linear models for dynamic pricing with demand learning. Management Science, 61(4), 723-739. https://doi.org/10.1287/ mnsc.2014.2031.

Bitran, G., \& Caldentey, R. (2003). An overview of pricing models for revenue management. Manufacturing \& Service Operations Management, 5(3), 203-229. https://doi.org/10.1287/ msom.5.3.203.16031.

Bitran, G. R., \& Mondschein, S. V. (1997). Periodic pricing of seasonal products in retailing. Management Science, 43(1), 64-79. https ://doi.org/10.1287/mnsc.43.1.64. 
Bock, C. (2016). Preserve personal freedom in networked societies. Nature, 537(7618), 9. https://doi.org/10.1038/537009a.

Bolton, L. E., Keh, H. T., \& Alba, J. W. (2010). How do price fairness perceptions differ across culture? Journal of Marketing Research, 47(3), 564-576. https://doi.org/10.1509/jmkr.47.3.564.

Bouchet, A., Troilo, M., \& Walkup, B. R. (2016). Dynamic pricing usage in sports for revenue management. Managerial Finance, 42(9), 913-921. https://doi.org/10.1108/MF-01-2016-0017.

Bront, J. J. M., Méndez-Díaz, I., \& Vulcano, G. (2009). A column generation algorithm for choice-based network revenue management. Operations Research, 57(3), 769-784. https://doi. org/10.1287/opre.1080.0567.

Brumelle, S. L., \& McGill, J. I. (1993). Airline seat allocation with multiple nested fare classes. Operations Research, 41(1), 127137. https://doi.org/10.1287/opre.41.1.127.

Buhmann, A., Paßmann, J., \& Fieseler, C. (2019). Managing algorithmic accountability: Balancing reputational concerns, engagement strategies, and the potential of rational discourse. Journal of Business Ethics. https://doi.org/10.1007/s1055 1-019-04226-4.

Calvano, E., Calzolari, G., Denicolò, V., \& Pastorello, S. (2019). Algorithmic pricing what implications for competition policy? Review of Industrial Organization, 55(1), 155-171. https://doi. org/10.1007/s11151-019-09689-3.

Caplan, B., \& Stringham, E. P. (2008). Privatizing the adjudication of disputes. Theoretical Inquiries in Law, 9(2), 503-528. https:// doi.org/10.2202/1565-3404.1195.

Chen, L. (2017). Measuring algorithms in online marketplaces. ProQuest Dissertations and Theses, 149. https://repository.libra ry.northeastern.edu/files/neu:cj82q9886.

Chen, M., \& Chen, Z. L. (2015). Recent developments in dynamic pricing research: Multiple products, competition, and limited demand information. Production and Operations Management, 24(5), 704-731. https://doi.org/10.1111/poms.12295.

Chen, N., \& Gallego, G. (2019). Welfare analysis of dynamic pricing. Management Science, 65(1), 139-151. https://doi.org/10.1287/ mnsc.2017.2943.

Chen, Y., \& Iyer, G. (2001). Research note: Consumer addressability and customized pricing. Marketing Science, 21(2), 197-208. https://doi.org/10.1287/mksc.21.2.197.153.

Chen, Q. G., Jasin, S., \& Duenyas, I. (2016a). Real-time dynamic pricing with minimal and flexible price adjustment. Management Science, 62(8), 2437-2455. https://doi.org/10.1287/ mnsc.2015.2238.

Chen, L., Mislove, A., \& Wilson, C. (2016). An empirical analysis of algorithmic pricing on amazon marketplace. In Proceedings of the 25th International Conference on World Wide Web$W W W^{\prime} 16$ (pp. 1339-1349). New York: ACM Press. https://doi. org/10.1145/2872427.2883089.

Chen, M. K., \& Sheldon, M. (2016). Dynamic pricing in a labor market: Surge pricing and flexible work on the uber platform. In Proceedings of the 2016 ACM conference on economics and computation. https://doi.org/10.1145/2940716.2940798.

Chen, Y., \& Sudhir, K. (2004). When shopbots meet emails: Implications for price competition on the Internet. Quantitative Marketing and Economics, 2(3), 233-255. https://doi.org/10.2139/ ssrn.291199.

Cho, M., Fan, M., \& Zhou, Y.-P. (2009). Strategic consumer response to dynamic pricing of perishable products. In C. Tang \& S. Netessine (Eds.), Consumer-driven demand and operations management models (pp. 435-458). Boston, MA: Springer. https:// doi.org/10.1007/978-0-387-98026-3_17.

Choe, C., King, S., \& Matsushima, N. (2018). Pricing with cookies: Behavior-based price discrimination and spatial competition. Management Science, 64(12), 5669-5687. https://doi. org/10.1287/mnsc.2017.2873.
Choe, P., \& Wu, J. (2015). Customer perceptions toward dynamic pricing for wireless data service. International Journal of Mobile Communications, 13(2), 172. https://doi.org/10.1504/ IJMC.2015.067962.

Choudhary, V., Ghose, A., Mukhopadhyay, T., \& Rajan, U. (2005). Personalized pricing and quality differentiation. Management Science, 51(7), 1120-1130. https://doi.org/10.1287/ mnsc. 1050.0383 .

Coffey, H. (2018). Airlines face crack down on use of 'exploitative' algorithm that splits up families on flights. The Independent. Retrieved July 26, 2019 from https://www.independent.co.uk/ travel/news-and-advice/airline-flights-pay-extra-to-sit-togethersplit-up-family-algorithm-minister-a8640771.html.

Cohen, M. C. (2018). Big data and service operations. Production and Operations Management, 27(9), 1709-1723. https://doi. org/10.1111/poms.12832.

Cohen, M. C., Lobel, R., \& Perakis, G. (2018). Dynamic pricing through data sampling. Production and Operations Management, 27(6), 1074-1088. https://doi.org/10.1111/poms.12854.

Cormen, T. H., Leiserson, C. E., Rivest, R. L., \& Stein, C. (2009). Introduction to algorithms (3rd ed.). Cambridge: MIT Press.

Cosguner, K., Chan, T. Y., \& Seetharaman, P. B. (2018). Dynamic pricing in a distribution channel in the presence of switching costs. Management Science, 64(3), 1212-1229. https://doi. org/10.1287/mnsc.2016.2649.

Cox, J. (2017). London terror attack: Uber slammed for being slow to turn off 'surge pricing' after rampage. The Independent. Retrieved April 28, 2018 from https://www.independent.co. uk/news/uk/home-news/london-terror-attack-uber-criticised -surge-pricing-after-london-bridge-black-cab-a 7772246.html.

Dakers, M. (2016). Uber knows customers with dying batteries are more likely to accept surge pricing. The Telegraph. Retrieved October 30, 2017 from http://www.telegraph.co.uk/busin ess/2016/05/22/uber-app-can-detect-when-a-users-phone-isabout-to-die/.

Danziger, S., Hadar, L., \& Morwitz, V. G. (2014). Retailer pricing strategy and consumer choice under price uncertainty. Journal of Consumer Research, 41(3), 761-774. https://doi. org/10.1086/677313.

Das, T. K., Gosavi, A., Mahadevan, S., \& Marchalleck, N. (1999). Solving semi-markov decision problems using average reward reinforcement learning. Management Science, 45(4), 560-574. https://doi.org/10.1287/mnsc.45.4.560.

de Laat, P. B. (2018). Algorithmic decision-making based on machine learning from big data: Can transparency restore accountability? Philosophy \& Technology, 31(4), 525-541. https://doi.org/10.1007/s13347-017-0293-z.

Decker, S., \& Saitto, S. (2014). Uber seeks to patent pricing surges that critics call gouging. Bloomberg. Retrieved May 3, 2018 from https://www.bloomberg.com/news/articles/2014-12-18/ uber-seeks-to-patent-pricing-surges-that-critics-call-gouging.

den Boer, A. V. (2015). Dynamic pricing and learning: Historical origins, current research, and new directions. Surveys in Operations Research and Management Science, 20(1), 1-18. https:// doi.org/10.1016/j.sorms.2015.03.001.

Dierksmeier, C. (2016). Reframing economic ethics: The philosophical foundations of humanistic management. London/New York: Palgrav Macmillan Publishers.

Dierksmeier, C. (2018). Qualitative freedom and cosmopolitan responsibility. Humanistic Management Journal, 2(2), 109123. https://doi.org/10.1007/s41463-017-0029-3.

Dierksmeier, C., \& Seele, P. (2016). Cryptocurrencies and business ethics. Journal of Business Ethics. https://doi.org/10.1007/ s10551-016-3298-0.

Dilmé, F., \& Li, F. (2019). Revenue management without commitment: Dynamic pricing and periodic flash sales. The Review of 
Economic Studies, 86(5), 1999-2034. https://doi.org/10.1093/ restud/rdy073.

Dopfer, K., Foster, J., \& Potts, J. (2004). Micro-meso-macro. Journal of Evolutionary Economics, 14(3), 263-279. https://doi. org/10.1007/s00191-004-0193-0.

Elegido, J. M. (2009). The just price: Three insights from the Salamanca School. Journal of Business Ethics, 90(1), 29-46. https ://doi.org/10.1007/s10551-008-0024-6.

Elegido, J. M. (2011). The ethics of price discrimination. Business Ethics Quarterly, 21(04), 633-660. https://doi.org/10.5840/ beq201121439.

Elegido, J. M. (2015). The just price as the price obtainable in an open market. Journal of Business Ethics, 130(3), 557-572. https://doi. org/10.1007/s10551-014-2240-6.

Ellickson, P. B., Misra, S., \& Nair, H. S. (2012). Repositioning dynamics and pricing strategy. Journal of Marketing Research, 49(6), 750-772. https://doi.org/10.1509/jmr.11.0068.

Elmaghraby, W., \& Keskinocak, P. (2003). Dynamic pricing in the presence of inventory considerations: Research overview, current practices, and future directions. Management Science, 49(10), 1287-1309. https://doi.org/10.1287/mnsc.49.10.1287.17315.

Esposito, E. (2017). Algorithmic memory and the right to be forgotten on the web. Big Data \& Society, 4(1), 205395171770399. https ://doi.org/10.1177/2053951717703996.

Esteves, R. B. (2014). Price discrimination with private and imperfect information. Scandinavian Journal of Economics, 116(3), 766-796. https://doi.org/10.1111/sjoe.12061.

Ettl, M., Harsha, P., Papush, A., \& Perakis, G. (2019). A data-driven approach to personalized bundle pricing and recommendation. Manufacturing \& Service Operations Management. https://doi. org/10.1287/msom.2018.0756.

Ezrachi, A., \& Stucke, M. E. (2016). The rise of behavioural discrimination. European Competition Law Review, 37(12), 485-492. https://doi.org/10.2139/ssrn.2830206.

Faruqui, A., Hledik, R., \& Tsoukalis, J. (2009). The power of dynamic pricing. The Electricity Journal, 22(3), 42-56. https://doi. org/10.1016/j.tej.2009.02.011.

Faruqui, A., \& Palmer, J. (2011). Dynamic Pricing of Electricity and its Discontents. The Brattle Group, online document. Retrieved December 10, 2016 from http://assets.fiercemarkets.net/public/ smartgridnews/Dynamic_Pricing_of_Electricity_and_its_Disco ntents_1.pdf.

Faruqui, A., \& Sergici, S. (2010). Household response to dynamic pricing of electricity: A survey of 15 experiments. Journal of Regulatory Economics, 38(2), 193-225. https://doi.org/10.1007/ s11149-010-9127-y.

Faruqui, A., \& Sergici, S. (2013). Arcturus: International evidence on dynamic pricing. The Electricity Journal, 26(7), 55-65. https:// doi.org/10.1016/j.tej.2013.07.007.

Feldman, D., Trzcinka, C., \& Winer, R. S. (2015). Pricing under noisy signaling. Review of Quantitative Finance and Accounting, 45(2), 435-454. https://doi.org/10.1007/s11156-014-0442-8.

Feng, Q. (2010). Integrating dynamic pricing and replenishment decisions under supply capacity uncertainty. Management Science, 56(12), 2154-2172. https://doi.org/10.1287/mnsc.1100.1238.

Feng, L., Zhang, J., \& Tang, W. (2015). A joint dynamic pricing and advertising model of perishable products. Journal of the Operational Research Society, 66(8), 1341-1351. https://doi. org/10.1057/jors.2014.89.

Fisher, M., Gallino, S., \& Li, J. (2018). Competition-based dynamic pricing in online retailing: A methodology validated with field experiments. Management Science, 64(6), 2496-2514. https:// doi.org/10.1287/mnsc.2017.2753.

Gal, M. S. (2017). Algorithmic-facilitated coordination: Market and legal solutions. CPI Antitrust Chronicle, May. Retrieved from https://www.competitionpolicyinternational.com/wp-content/ uploads/2017/05/CPI-Gal.pdf.

Gal, M. S. (2019). Illegal pricing algorithms. Communications of the ACM, 62(1), 18-20. https://doi.org/10.1145/3292515.

Gallego, G., \& Talebian, M. (2012). Demand learning and dynamic pricing for multi-version products. Journal of Revenue and Pricing Management, 11(3), 303-318. https://doi.org/10.1057/ rpm.2010.36.

Gallego, G., \& van Ryzin, G. (1994). Optimal dynamic pricing of inventories with stochastic demand over finite horizons. Management Science, 40(8), 999-1020. https://doi.org/10.1287/ mnsc.40.8.999.

Garbarino, E., \& Lee, O. F. (2003). Dynamic pricing in internet retail: Effects on consumer trust. Psychology and Marketing, 20(6), 495-513. https://doi.org/10.1002/mar.10084.

Garbarino, E., \& Maxwell, S. (2010). Consumer response to normbreaking pricing events in e-commerce. Journal of Business Research, 63(9-10), 1066-1072. https://doi.org/10.1016/j.jbusr es.2008.12.010.

Gosavi, A. (2004a). Reinforcement learning for long-run average cost. European Journal of Operational Research, 155(3), 654-674. https://doi.org/10.1016/S0377-2217(02)00874-3.

Gosavi, A. (2004b). A reinforcement learning algorithm based on policy iteration for average reward: Empirical results with yield management and convergence analysis. Machine Learning, 55(1), 5-29. https://doi.org/10.1023/B:MACH.0000019802 $.64038 .6 \mathrm{c}$.

Gössling, T., \& van Liedekerke, L. (2014). Editorial: The caring organisation. Journal of Business Ethics, 120(4), 437-440. https://doi org/10.1007/s10551-014-2158-z.

Gratwohl, N. (2019). Der kassenlose Laden kommt in die Schweiz: Wird bald auch Gesichtserkennung eingesetzt? Neue Zürcher Zeitung. Retrieved from August 27, 2019 from https://www. nzz.ch/wirtschaft/kassenlose-laeden-sind-auf-dem-vormarschld. 1504205 .

Green, P. E. (1963). Bayesian decision theory in pricing strategy. Journal of Marketing, 27(1), 5. https://doi.org/10.2307/1248574.

Gu, Y., \& Wenzel, T. (2014). Strategic obfuscation and consumer protection policy. The Journal of Industrial Economics, 62(4), 632-660. https://doi.org/10.1111/joie.12060.

Haws, K. L., \& Bearden, W. O. (2006). Dynamic pricing and consumer fairness perceptions. Journal of Consumer Research, 33(3), 304311. https://doi.org/10.1086/508435.

Helberger, N. (2013). Freedom of expression and the Dutch CookieWall. Amsterdam Law School, Paper (No. 2013-66). https://doi. org/10.2139/ssrn.2197251.

Helbing, D., \& Seele, P. (2018). When code is law, algorithms must be made transparent. Retrieved April 12, 2019 from http://futur ict.blogspot.com/2018/12/when-code-is-law-algorithms-must-be. html.

Hinz, O., Hann, I. H., \& Spann, M. (2011). Price discrimination in E-commerce? an examination of dynamic pricing in nameyour-own price markets. MIS Quarterly, 35(1), 81. https://doi. org/10.2307/23043490.

Ho, Y.-C., Ho, Y.-J., \& Tan, Y. (2017). Online cash-back shopping: Implications for consumers and e-businesses. Information Systems Research, 28(2), 250-264. https://doi.org/10.1287/ isre.2017.0693.

Hoffmann, F., Inderst, R., \& Ottaviani, M. (2013). Hypertargeting, limited attention, and privacy: Implications for marketing and campaigning. SSRN Electronic Journal. https://doi.org/10.2139/ ssrn. 2395208.

Huang, K. (2010). Equilibrium market segmentation for targeted pricing based on customer characteristics. SSRN Electronic Journal. https://doi.org/10.2139/ssrn.1292508. 
Huang, Y.-S., Hsu, C.-S., \& Ho, J.-W. (2014). Dynamic pricing for fashion goods with partial backlogging. International Journal of Production Research, 52(14), 4299-4314. https://doi. org/10.1080/00207543.2014.881576.

Ittoo, A., \& Petit, N. (2017). Algorithmic pricing agents and tacit collusion: A technological perspective. SSRN Electronic Journal. https://doi.org/10.2139/ssrn.3046405.

Johnson, D. G. (2015). Technology with no human responsibility? Journal of Business Ethics, 127(4), 707-715. https://doi. org/10.1007/s10551-014-2180-1.

Kalayc1, K. (2016). Confusopoly: Competition and obfuscation in markets. Experimental Economics, 19(2), 299-316. https://doi. org/10.1007/s10683-015-9438-z.

Karr, D. (2018). How to use algorithmic pricing to maximize profits. MarTech Blog. Retrieved July 2, 2018 from https://martech.zone/ algorithmic-pricing-maximize-profits/.

Keskin, N. B., \& Zeevi, A. (2014). Dynamic pricing with an unknown demand model: Asymptotically optimal semi-myopic policies. Operations Research, 62(5), 1142-1167. https://doi.org/10.1287/ opre.2014.1294.

Kincaid, W. M., \& Darling, D. A. (1963). An inventory pricing problem. Journal of Mathematical Analysis and Applications, 7(2), 183-208. https://doi.org/10.1016/0022-247X(63)90047-7.

Koh, B., Raghunathan, S., \& Nault, B. R. (2017). Is voluntary profiling welfare enhancing? MIS Quarterly, 41(1), 23-41. https://doi. org/10.25300/MISQ/2017/41.1.02.

Kopalle, P. K., Rao, A. G., \& Assunção, J. L. (1996). Asymmetric reference price effects and dynamic pricing policies. Marketing Science, 15(1), 60-85. https://doi.org/10.1287/mksc.15.1.60.

Kraemer, F., van Overveld, K., \& Peterson, M. (2011). Is there an ethics of algorithms? Ethics and Information Technology, 13(3), 251-260. https://doi.org/10.1007/s10676-010-9233-7.

Kremer, M., Mantin, B., \& Ovchinnikov, A. (2017). Dynamic pricing in the presence of myopic and strategic consumers: Theory and experiment. Production and Operations Management, 26(1), 116-133. https://doi.org/10.1111/poms.12607.

Kummer, M., \& Schulte, P. (2019). When private information settles the bill: Money and privacy in Google's market for smartphone applications. Management Science, 65(8), 3470-3494. https:// doi.org/10.1287/mnsc.2018.3132.

Lee, D. J., Ahn, J. H., \& Bang, Y. (2011). Managing consumer privacy concerns in personalization: A strategic analysis of privacy protection. MIS Quarterly, 35(2), 423. https://doi.org/10.2307/23044 050 .

Lee, F., \& Monroe, K. B. (2008). Dynamic pricing on the internet: A price framing approach. Advances in Consumer Research, 35(2005), 637-638. http://search.ebscohost.com/login.aspx?direc $\mathrm{t}=$ true $\& \mathrm{db}=$ buh \& $\mathrm{AN}=35063834 \&$ site $=$ ehost-live.

Leonhardt, D. (2005). Why variable pricing fails at the vending machine. The New York Times. Retrieved June 10, 2019 from https://www.nytimes.com/2005/06/27/business/why-variablepricing-fails-at-the-vending-machine.html.

Levin, Y., McGill, J., \& Nediak, M. (2008). Risk in revenue management and dynamic pricing. Operations Research, 56(2), 326343. https://doi.org/10.1287/opre.1070.0438.

Li, T., Sethi, S. P., \& He, X. (2015a). Dynamic pricing, production, and channel coordination with stochastic learning. Production and Operations Management, 24(6), 857-882. https://doi. org/10.1111/poms.12320.

Li, S., Zhang, J., \& Tang, W. (2015b). Joint dynamic pricing and inventory control policy for a stochastic inventory system with perishable products. International Journal of Production Research, 53(10), 2937-2950. https://doi.org/10.1080/00207 543.2014.961206.
Liu, Q., \& van Ryzin, G. J. (2008). Strategic capacity rationing to induce early purchases. Management Science, 54(6), 1115-1131. https://doi.org/10.1287/mnsc.1070.0832.

Maglaras, C., \& Meissner, J. (2006). Dynamic pricing strategies for multiproduct revenue management problems. Manufacturing \& Service Operations Management, 8(2), 136-148. https://doi. org/10.1287/msom.1060.0105.

Martin, K. (2018). Ethical implications and accountability of algorithms. Journal of Business Ethics. https://doi.org/10.1007/s1055 1-018-3921-3.

Martin, K. (2019a). Designing ethical algorithms. MIS Quarterly Executive, 2019(2016), 129-142. https://doi.org/10.17705/2msqe .00012 .

Martin, N. (2019). Uber charges more if they think you're willing to pay more. Forbes. Retrieved July 28, 2019 from https://www. forbes.com/sites/nicolemartin1/2019/03/30/uber-charges-moreif-they-think-youre-willing-to-pay-more/\#17206e573654.

Martin, K. D., \& Murphy, P. E. (2017). The role of data privacy in marketing. Journal of the Academy of Marketing Science, 45(2), 135-155. https://doi.org/10.1007/s11747-016-0495-4.

Matsumura, T., \& Matsushima, N. (2015). Should firms employ personalized pricing? Journal of Economics \& Management Strategy, 24(4), 887-903. https://doi.org/10.1111/jems.12109.

Maxwell, S., \& Garbarino, E. (2010). The identification of social norms of price discrimination on the internet. Journal of Product \& Brand Management, 19(3), 218-224. https://doi. org/10.1108/10610421011046193.

Mehra, S. K. (2016). Antitrust and the robo-seller: Competition in the time of algorithms. CPI Antitrust Chronicle, 100(4), 13231375. http://www.minnesotalawreview.org/wp-content/uploa ds/2016/04/Mehra_ONLINEPDF1.pdf.

Mercier-Roy, M., \& Mailhot, C. (2019). What's in an app? Investigating the moral struggles behind a sharing economy device. Journal of Business Ethics. https://doi.org/10.1007/s10551-019-04207-7.

Miklós-Thal, J., \& Tucker, C. (2019). Collusion by algorithm: Does better demand prediction facilitate coordination between sellers? Management Science, 65(4), 1552-1561. https://doi.org/10.1287/ mnsc.2019.3287.

Mittelstadt, B. D., Allo, P., Taddeo, M., Wachter, S., \& Floridi, L. (2016). The ethics of algorithms: Mapping the debate. Big Data \& Society, 3(2), 1-21. https://doi.org/10.1177/205395171667967 9.

Monsalve, F. (2014). Scholastic just price versus current market price: Is it merely a matter of labelling? European Journal of the History of Economic Thought, 21(1), 4-20. https://doi. org/10.1080/09672567.2012.683019.

Obermiller, C., Arnesen, D., \& Cohen, M. (2012). Customized pricing: Win-win or end run? Drake Management Review, 1(2), 12-28.

Oxera Consulting LLP. (2017). When algorithms set prices: winners and losers. Discussion paper. Retrieved June 25, 2018 from https ://www.oxera.com/Latest-Thinking/Agenda/2017/When-algor ithms-set-prices-winners-and-losers.aspx.

Oxford Dictionary. (2019). Algorithm: Definition of algorithm. Retrieved September 5, 2019 from https://www.lexico.com/en/ definition/algorithm.

Özer, Ö., \& Zheng, Y. (2016). Markdown or everyday low price? The role of behavioral motives. Management Science, 62(2), 326346. https://doi.org/10.1287/mnsc.2014.2147.

Peura, H., \& Bunn, D. W. (2015). Dynamic pricing of peak production. Operations Research, 63(6), 1262-1279. https://doi.org/10.1287/ opre.2015.1429.

Phillips, R. L. (2005). Pricing and revenue optimization. Stanford, CA: Stanford University Press.

PYMNTS. (2018). In-store tracking tech gets personalized. PYMNTS. com. Retrieved August 25, 2019 from https://www.pymnts.com/ 
news/retail/2018/adobe-retail-apocalypse-personalization-brick -and-mortar/.

Radner, R., Radunskaya, A., \& Sundararajan, A. (2014). Dynamic pricing of network goods with boundedly rational consumers. Proceedings of the National Academy of Sciences, 111(1), 99-104. https://doi.org/10.1073/pnas.1319543110.

Ray, S., Li, S., \& Song, Y. (2005). Tailored supply chain decision making under price-sensitive stochastic demand and delivery uncertainty. Management Science, 51(12), 1873-1891. https:// doi.org/10.1287/mnsc.1050.0452.

Rayna, T., Darlington, J., \& Striukova, L. (2015). Pricing music using personal data: Mutually advantageous first-degree price discrimination. Electronic Markets, 25(2), 139-154. https://doi. org/10.1007/s12525-014-0165-7.

Richards, T. J., Liaukonyte, J., \& Streletskaya, N. A. (2016). Personalized pricing and price fairness. International Journal of Industrial Organization, 44, 138-153. https://doi.org/10.1016/j.ijind org.2015.11.004.

Robbins, H., \& Monro, S. (1951). A stochastic approximation method. The Annals of Mathematical Statistics, 22(3), 400-407. https:// www.jstor.org/stable/2236626.

Rochelle, M. (2019). Press \& media. Wasteless. Retrieved July 29, 2019 from https://www.wasteless.co/press.

Rossi, P. E., Allenby, G. M., \& McCulloch, R. E. (2012). Bayesian statistics and marketing. Chichester: Wiley.

Rust, R. T., \& Chung, T. S. (2006). Marketing models of service and relationships. Marketing Science, 25(6), 560-580. https://doi. org/10.1287/mksc.1050.0139.

Schechner, S. (2017). Why do gas station prices constantly change? Blame the algorithm. The Wall Street Journal. Retrieved August 18, 2019 from https://www.wsj.com/articles/why-do-gas-stationprices-constantly-change-blame-the-algorithm-1494262674.

Schmidt, F. L., \& Hunter, J. E. (2014). Methods of meta-analysis. London: SAGE Publications Inc.

Schwalbe, U. (2018). Algorithms, machine learning, and collusion. Journal of Competition Law \& Economics, 14(4), 568-607. https ://doi.org/10.1093/joclec/nhz004.

Schwartz, A. (1993). A reinforcement learning method for maximizing undiscounted rewards. In Machine Learning Proceedings 1993 (pp. 298-305). Amsterdam: Elsevier. https://doi.org/10.1016/ b978-1-55860-307-3.50045-9.

Snyder, J. (2012). What's the matter with price gouging? Business Ethics Quarterly, 19(02), 275-293. https://doi.org/10.5840/beq20 0919214.

Song, Y., Ray, S., \& Boyaci, T. (2009). Technical note: Optimal dynamic joint inventory-pricing control for multiplicative demand with fixed order costs and lost sales. Operations Research, 57(1), 245-250. https://doi.org/10.1287/ opre.1080.0530.

Soo, Z. (2017). BingoBox to expand its unstaffed store concept beyond mainland China. South China Morning Post. Retrieved January 29, 2019 from http://www.scmp.com/tech/start-ups/ article/2121799/bingobox-bring-unmanned-convenience-store s-hong-kong-next-year.

Spann, M., Fischer, M., \& Tellis, G. J. (2015). Skimming or penetration? Strategic dynamic pricing for new products. Marketing Science, 34(2), 235-249. https://doi.org/10.1287/mksc.2014.0891.

Steppe, R. (2017). Online price discrimination and personal data: A general data protection regulation perspective. Computer Law and Security Review, 33(6), 768-785. https://doi.org/10.1016/j. clsr.2017.05.008

Stucke, M. E., \& Ezrachi, A. (2016). How pricing bots could form cartels and make things more expensive. Harvard Business Review. Retrieved July 15, 2019 from https://hbr.org/2016/10/how-prici ng-bots-could-form-cartels-and-make-things-more-expensive.
Suddaby, R., Bitektine, A., \& Haack, P. (2017). Legitimacy. Academy of Management Annals, 11(1), 451-478.

Tan, Y. R., Paul, A. A., Deng, Q., \& Wei, L. (2017). Mitigating inventory overstocking: Optimal order-up-to level to achieve a target fill rate over a finite horizon. Production and Operations Management, 26(11), 1971-1988. https://doi.org/10.1111/ poms. 12750 .

Tanner, A. (2014). Different customers, different prices, thanks to big data. Forbes. Retrieved August 18, 2019 from https://www.forbe s.com/sites/adamtanner/2014/03/26/different-customers-diffe rent-prices-thanks-to-big-data/\#6c6d11505730.

Thaler, R. (1985). Mental accounting and consumer choice. Marketing Science, 4(3), 199-214. https://doi.org/10.1287/mksc.4.3.199.

Townley, C., Morrison, E., \& Yeung, K. (2017). Big data and personalized price discrimination in EU Competition law. Yearbook of European Law, 36(1), 683-748. https://doi.org/10.1093/yel/ yex015.

UK Competition and Markets Authority. (2018). Pricing algorithms: Economic working paper on the use of algorithms to facilitate collusion and personalised pricing. Crown. Retrieved July 25, 2019 from https://assets.publishing.service.gov.uk/government/ uploads/system/uploads/attachment_data/file/746353/Algorithms _econ_report.pdf.

van Ryzin, G., \& McGill, J. (2000). Revenue management without forecasting or optimization: An adaptive algorithm for determining airline seat protection levels. Management Science, 46(6), 760-775. https://doi.org/10.1287/mnsc.46.6.760.11936.

Van Uytsel, S. (2018). Artificial intelligence and collusion: A literature overview. In Robotics, AI and the future of law, perspectives in law, business and innovation (pp. 155-182). Singapore: Springer. https://doi.org/10.1007/978-981-13-2874-9_7.

Waldfogel, J. (2015). First degree price discrimination goes to school. Journal of Industrial Economics, 63(4), 569-597. https://doi. org/10.1111/joie.12085.

Weisstein, F. L., Monroe, K. B., \& Kukar-Kinney, M. (2013). Effects of price framing on consumers' perceptions of online dynamic pricing practices. Journal of the Academy of Marketing Science, 41(5), 501-514. https://doi.org/10.1007/s11747-013-0330-0.

Wolak, F. (2016). Designing nonlinear price schedules for urban water utilities to balance revenue and conservation goals. National Bureau of Economic Research Working Paper 22503, 1-41. https ://doi.org/10.1017/cbo9781107415324.004.

Wu, S., Hitt, L. M., Chen, P., \& Anandalingam, G. (2008). Customized bundle pricing for information goods: A nonlinear mixed-integer programming approach. Management Science, 54(3), 608-622. https://doi.org/10.1287/mnsc.1070.0812.

Xia, F., Chatterjee, R., \& May, J. H. (2019). Using conditional restricted boltzmann machines to model complex consumer shopping patterns. Marketing Science, 38(4), 711-727. https:// doi.org/10.1287/mksc.2019.1162.

Xia, L., Monroe, K. B., \& Cox, J. L. (2004). The price is unfair! A conceptual framework of price fairness perceptions. Journal of Marketing, 68(4), 1-15. https://doi.org/10.1509/jmkg.68.4.1.42733.

Xiao, G., Yang, N., \& Zhang, R. (2015). Dynamic pricing and inventory management under fluctuating procurement costs. Manufacturing \& Service Operations Management, 17(3), 321-334. https ://doi.org/10.1287/msom.2015.0519.

Xiong, Y., Li, G., \& Fernandes, K. J. (2010). Dynamic pricing model and algorithm for perishable products with fuzzy demand. Applied Stochastic Models in Business and Industry, 26(6), 758-774. https://doi.org/10.1002/asmb.816.

Xu, Z., \& Dukes, A. (2019). Product line design under preference uncertainty using aggregate consumer data. Marketing Science, 38(4), 669-689. https://doi.org/10.1287/mksc.2019.1160. 
Zenger, H. (2012). The marginal price effects of antitrust rules against price discrimination. Economics Letters, 117(3), 921-923. https ://doi.org/10.1016/j.econlet.2012.07.017.

Zerilli, J., Knott, A., Maclaurin, J., \& Gavaghan, C. (2018). Transparency in algorithmic and human decision-making: Is there a double standard? Philosophy \& Technology. https://doi.org/10.1007/ s13347-018-0330-6.

Zhang, J. (2011). The perils of behavior-based personalization. Marketing Science, 30(1), 170-186. https://doi.org/10.1287/ mksc. 1100.0607 .

Zhang, Y., Mantin, B., \& Wu, Y. (2019). Inventory decisions in the presence of strategic customers: Theory and behavioral evidence. Production and Operations Management, 28(2), 374-392. https ://doi.org/10.1111/poms.12926.

Zhou, S. X., \& Chao, X. (2014). Dynamic pricing and inventory management with regular and expedited supplies. Production and Operations Management, 23(1), 65-80. https://doi.org/10.1111/ poms.12047.
Zuboff, S. (2019). The age of surveillance capitalism: The fight for a human future at the new frontier of power. London: Profile Books Ltd. https://www.publicaffairsbooks.com/titles/shosh ana-zuboff/the-age-of-surveillance-capitalism/9781610395694/.

Zuiderveen Borgesius, F., \& Poort, J. (2017). Online price discrimination and EU data privacy law. Journal of Consumer Policy, 40(3), 347-366. https://doi.org/10.1007/s10603-017-9354-z.

Zwolinski, M. (2008). The ethics of price gouging. Business Ethics Quarterly, 18(03), 347-378. https://doi.org/10.5840/beq2008183 27.

Zwolinski, M. (2009). Dialogue on price gouging. Business Ethics Quarterly, 19(2), 295-303.

Publisher's Note Springer Nature remains neutral with regard to jurisdictional claims in published maps and institutional affiliations. 